\title{
Intra-articular treatment options for knee osteoarthritis
}

\author{
Ian A. Jones ${ }^{1}$, Ryan Togashi ${ }^{1}$, Melissa L. Wilson ${ }^{2}$, Nathanael Heckmann ${ }^{1}$, and C. Thomas \\ Vangsness $\mathrm{Jr}^{1}{ }^{\text {* }}$ \\ ${ }^{1}$ Keck School of Medicine of USC, Department of Orthopaedic Surgery, Los Angeles, CA, USA. \\ ${ }^{2}$ Keck School of Medicine of USC, Department of Preventive Medicine, Los Angeles, CA, USA.
}

\begin{abstract}
Intra-articular drug delivery has a number of advantages over systemic administration; however, for the past 20 years, intra-articular treatment options for the management of knee osteoarthritis (OA) have been limited to analgesics, glucocorticoids, hyaluronic acid (HA) and a small number of unproven alternative therapies. Although HA and glucocorticoids can provide clinically meaningful benefits to an appreciable number of patients, emerging evidence indicates that the apparent effectiveness of these treatments is largely a result of other factors, including the placebo effect. Biologic drugs that target inflammatory processes are used to manage rheumatoid arthritis, but have failed to translate to OA. A lack of high-level evidence and methodological limitations hinder our understanding of so called 'stem' cell therapies and, although the off-label administration of intra-articular cell therapies (such as platelet-rich plasma and bone marrow aspirate concentrate) is common, high-quality clinical data is needed before these treatments can be recommended. A number of promising intra-articular treatments are currently in clinical development in the United States, including small-molecule and biologic therapies, devices, and gene therapies. Although the prospect of new, non-surgical treatments for OA is exciting, the benefits new treatments must be carefully weighed against their costs and potential risks.
\end{abstract}

\section{Graphical Abstract}

Intra-articular therapies for knee osteoarthritis (OA) are causing excitement among clinicians and patients, but care should be taken when choosing which therapy to use. In this Review, Vangsness and colleagues critically appraise current and future intra-articular therapies for knee OA.

\footnotetext{
*vangsnes@usc.edu.

Author contributions

All authors researched data for the article, made a substantial contribution to discussions of content, wrote the article and reviewed and/or edited the manuscript before submission.

Competing interests

I.A.J., R.T., M.L.W. and N.H. declare no competing interests. C.T.V.Jr. declares that he holds shares in CarthroniX Inc. and in Parcus Medical.

Publisher's note

Springer Nature remains neutral with regard to jurisdictional claims in published maps and institutional affiliations.
} 


\section{Introduction}

Osteoarthritis (OA) is a chronic and debilitating joint disease that causes damage to the articular cartilage and underlying bone ${ }^{1}$. Although commonly referred to as a 'wear and tear' disease, complex interactions between genetic, metabolic, biochemical, and biomechanical factors are also thought to be important in disease progression ${ }^{2,3}$. Indeed, osteoarthritic chondrocytes are not apoptotic, but degenerated and deranged, as evidenced by ultrastructural changes and an uncoordinated gene expression pattern ${ }^{4}$. Moreover, the whole joint is involved in the progression of the disease ${ }^{5}$ and the roles of the synovium, muscles and ligaments are likely to be underestimated ${ }^{6}$. Intra-articular drug delivery, in which a concentrated therapeutic dose is distributed throughout the joint capsule ${ }^{7}$, might be the ideal mode of drug delivery for OA therapies (Figure 1).

In this Review, we briefly introduce intra-articular therapies before critically appraising the evidence supporting the use of standard intra-articular treatment options. We also discuss clinical studies that have investigated single-molecule biologic therapies and provide a highlevel overview of cell-based therapies. Finally, we deliver an update on and a critical assessment of some of the most anticipated and promising intra-articular OA therapies currently in clinical development for the United States market. The surgical treatment of OA and the basic biology of the joint are not discussed in detail, as these topics have been covered extensively elsewhere ${ }^{8-11}$, as have other clinically investigated treatments ${ }^{12}$ and administration routes ${ }^{13}$.

\section{Intra-articular drug delivery}

Intra-articular drug delivery has a number of advantages over systemic delivery, including increased local bioavailability, reduced systemic exposure, fewer adverse events and reduced $\operatorname{cost}^{7,8}$. However, the efficacy of intra-articular therapies remains controversial and clinical guidelines regarding their use are often inconsistent with one another ${ }^{14,15}$. In addition, factors such as drug residence time ${ }^{16}$, systemic effects ${ }^{17}$ and administration technique ${ }^{18}$ contribute to treatment variability.

Intra-articular therapies are rapidly cleared from the synovial fluid by lymphatic drainage at a rate that largely depends on the size of the molecule. For example, the half-life of albumin in the joint is roughly 1-13 hours, whereas hyaluronic acid (HA) takes approximately 26 hours to clear the joint ${ }^{16}$. Additionally, the half-life of non-steroidal anti-inflammatory drugs (NSAIDs) and soluble steroids in the joint is only 1-4 hours ${ }^{19}$. Despite the short residence time of intra-articular therapies, studies frequently report effects that last several months. ${ }^{20}$ The mechanism behind these long-term effects is treatment-specific and is not well understood.

\section{The placebo effect}

When considering the evidence for or against an intra-articular therapy, it is important to understand that intra-articular injections have a strong placebo effect ${ }^{21}$. Self-reported parameters such as pain and stiffness are particularly responsive to intra-articular placebo ${ }^{22}$. In fact, the effect size of intra-articular placebo injections might be greater than that of both 
topical and oral placebos ${ }^{23}$. Although intra-articular therapies are widely used in the treatment of OA, it has long been thought that standard intra-articular treatment options (HA and glucocorticoids) provide conflicting benefit over joint aspiration alone for most patients ${ }^{24}$.

The strong placebo effect of intra-articular injections might account for the difficulty in detecting differences between treatment groups in clinical trials, especially when the difference between the groups is small. Even in patients who receive mock injections (an injection without therapeutic agent or placebo), the reported benefit is not statistically different to that of those who receive saline, lactic acid, procaine or hydrocortisone ${ }^{25}$. A 2017 meta-analysis showed the effect of intra-articular saline on pain scores (visual analogue scale (VAS) and Western Ontario and McMaster Universities osteoarthritis index (WOMAC)), revealing statistically significant differences at 6 months for both the VAS and the WOMAC score ${ }^{26}$.

\section{Interpreting clinical findings}

The degree to which a treatment affects the outcome of interest is called the effect size. Effect size is the most important statistic reported - not the $P$ value - because it communicates how effective the treatment is at alleviating OA symptoms. Any given treatment might or might not have a large effect on the clinical population, irrespective of its statistical significance of the outcomes of the treatment. When an effect size is very large, it suggests possible clinical significance even in the absence of statistical significance, as the latter is heavily dependent on sample size. Even studies that meet standard power parameters (80\% statistical power) still might not have sufficient power to detect a clinically significant difference (a type II error), which, by design, occurs $20 \%$ of the time. Likewise, a small effect size might be statistically significant, but could have little to no clinically meaningful significance.

A tool that can be used to understand the clinical relevance of reported differences is the minimal important difference (MID), also known as the minimal clinically important difference (MCID). The MID was originally defined as the smallest difference in score that patients perceive as beneficial ${ }^{27}$, and is most frequently calculated using the mean change method, which is the average score of patients reporting feeling 'slightly better' minus the average score of patients reporting that they feel 'about the same' 28,29 . In other words, the MID attempts to capture both the magnitude of the improvement and the value patients place on that improvement ${ }^{30}$.

A 2017 systematic review revealed plausible MID values for the WOMAC, the Knee Injury and Osteoarthritis Outcome Score (KOOS) and the European quality of life five-dimension questionnaire (EQ-5D) ${ }^{31}$. These estimates can be used to provide pretext when clinically appraising a treatment's effectiveness. However, MID cannot be used to assess individuals ${ }^{29}$ and does not take into account the overall risk-benefit ratio or the cost of a treatment ${ }^{32,33}$. In addition, MID should not be treated as a universal fixed value $e^{34,35}$, as it tends to vary by population, by context and by the calculation method used $32,36,37$. 


\section{Standard intra-articular treatments}

Glucocorticoids and HA are the most widely used intra-articular therapies. Although not categorically defined as standard-of-care, they are the standard intra-articular treatment option for the management of OA-related knee pain in patients who fail to respond to nonpharmacologic therapy, NSAIDs or analgesics. However, an emerging body of evidence exists that calls the efficacy of these therapies into question ${ }^{38}$ and an increasing number of professional organizations are questioning their appropriateness (Table 1).

Rather than putting forward specific treatment recommendations on the basis of existing evidence, the following sections explore several of the most widely cited and clinically used guidelines on the treatment of OA. The evidence supporting each recommendation is discussed to highlight potential strengths and weaknesses. Importantly, what is appropriate for the broader population of patients with OA might differ for specific sub-sets of patients, and some phenotypes of OA might respond to the standard treatment options differently than others $^{39}$. Additionally, efficacy should be carefully weighed against both the cost of the treatment and the potential risk of harm, especially when the efficacy of a given treatment is questionable.

\section{Glucocorticoids}

In their 2013 guidelines, the American Academy of Orthopaedic Surgeons (AAOS) found a lack of compelling evidence to support the use of glucocorticoids for the treatment of OA, as well as an unclear balance between benefits and potential harms of this treatment ${ }^{40}$. This recommendation was formed on the basis of the quality and generalizability of the included studies, which was determined in advance using an automated coding scheme. The final recommendation of the AAOS was made on the basis of six key studies, four of which were placebo-controlled trials that evaluated pain for at least 4 weeks ${ }^{41-44}$. The results of these studies were mixed, and they all included one or more flaws in their design. In lieu of the weak efficacy data of these studies ${ }^{41-44}$, as well as the results of other studies that suggested that glucocorticoid injections might be inferior to HA injections ${ }^{45}$ or tidal lavage ${ }^{46}$, the AAOS determined that inconclusive evidence existed to support the use of glucocorticoids for knee $\mathrm{OA}^{40}$.

Guidelines published in 2014 by the Osteoarthritis Research Society International $(\mathrm{OARSI})^{47}$ issued a more favourable recommendation than the AAOS, concluding that intraarticular glucocorticoid injections were 'appropriate' and that the quality of the evidence was 'good.' These conclusions were supported by the results of two systematic reviews ${ }^{48}$ that were published in 2009 and 2006. However, a close inspection of the data in conjunction with current evidence suggests that the OARSI guidelines ${ }^{47}$ might have overestimated the therapeutic efficacy of glucocorticoid injections. The authors of the 2009 systematic review concluded that glucocorticoids provided benefits over HA at 2 weeks, but not at 4, 8, 12 or 26 weeks. ${ }^{48}$ The authors of the 2006 systematic review, which was published in the Cochrane Database, took a favourable stance concerning the effectiveness of glucocorticoids than the authors of the 2009 review $^{49}$. However, an updated Cochrane meta-analysis published in 2015 showed that, although glucocorticoids seemed to offer small-to-moderate benefits over placebo for up to 6 weeks (standardized mean difference (SMD) $-0.41,95 \%$ 
CI -0.61 to -0.21 ), it was unclear whether the difference was clinically important. The authors also pointed out inconsistent and highly variable treatment effects, imprecise pooled estimates that did not rule out potentially relevant clinical effects, a high-to-unclear risk of bias, considerable heterogeneity between trials and evidence of small-study effects ${ }^{50}$.

The guidelines published by the National Institute for Health and Care Excellence (NICE) ${ }^{51}$ in 2014 and by the American College of Rheumatology (ACR) ${ }^{52}$ in 2012 both recommended glucocorticoids for patients with knee OA; however, both groups provided weak support for their recommendations. NICE recommended that glucocorticoid injections be considered as an adjunct to core treatments for the relief of moderate to severe pain in people with OA on the basis of the ability of glucocorticoids to provide short-term (1-4 weeks) pain relief ${ }^{51}$, but their recommendation relied on the out of date 2006 Cochrane Database review ${ }^{49}$ that was also referenced in the OARSI guidelines ${ }^{47}$ and failed to consider any literature published between 2006 and 2014. The ACR guidelines 'strongly' recommended glucocorticoid injections for patients who do not respond to full-dose paracetamol (acetaminophen), but provided no supporting references to justify this recommendation ${ }^{52}$.

Since the aforementioned recommendations were published, concern has increased around the detrimental catabolic effects that glucocorticoids have on cartilage ${ }^{53}$. For example, the results of a 2017 study suggested that administering glucocorticoid injections before total knee arthroplasty might increase the risk of postoperative infection ${ }^{54}$. Notably, the results of one study showed that patients who had been treated with intra-articular glucocorticoids (40 $\mathrm{mg}$ triamcinolone) had significantly greater cartilage volume loss than those who had been given intra-articular saline over a 2 year period (between group difference $-0.11 \mathrm{~mm}$; $95 \%$ CI -0.20 to $-0.03 \mathrm{~mm})^{55}$. This result is concerning because a $1 \%$ increase in the rate of tibial cartilage loss between baseline and 2 years corresponds to an $20 \%$ increase in the risk of undergoing knee replacement surgery at 4 years ${ }^{56}$ and because high rates of cartilage loss have been directly associated with an increased risk of undergoing arthroplasty ${ }^{57}$.

\section{Hyaluronic acid}

Clinical recommendations for the use of intra-articular HA for knee OA tend to be less favourable than those for glucocorticoid injections. The 2013 AAOS guidelines strongly recommend against the use of $\mathrm{HA}$ for symptomatic knee $\mathrm{OA}^{40}$. This recommendation was formed on the basis of a meta-analysis of 14 studies that showed an effect that was $<0.5$ MID units. The reliance of the AAOS guidelines ${ }^{40}$ on a MID of 0.5 on a five-point scale has prompted debate, with some researchers arguing that a MID should only be used as a supplementary instrument and not as a basis for clinical decision making ${ }^{58}$. However, the results of a 2017 systematic review $^{31}$ that aimed to establish credible anchor-based MID values for patients with OA support the approach taken by the AAOS. Nevertheless, a lack of treatment consensus in the orthopaedic community continues to persist, which has led to an apparent disconnect between what was recommended by the AAOS and what occurs in clinical practice ${ }^{59}$. The AAOS plans to publish updated guidelines at the end of 2018 that rely on findings from a 2018 network meta-analysis that showed the effect size of HA to have a weighted mean difference of -0.05 (CI: -0.12 to 0.01 ) compared with placebo for the assessment of pain ${ }^{60}$. 
The OARSI guidelines ${ }^{47}$ were more favourable towards HA than the AAOS guidelines ${ }^{40}$ and suggested that the efficacy of HA for knee OA was "uncertain". The recommendation of uncertain by OARSI was formed on the basis of three meta-analyses ${ }^{20,48,61}$. The first of these meta-analyses showed that the long-term effects of intra-articular HA were superior to intra-articular glucocorticoids ${ }^{48}$; however, HA was not compared with saline as a placebo in this study, which raises doubt over the validity of the conclusions. The second meta-analysis from 2011 compared HA to placebo and showed that the effect size favoured HA by week 4 $(0.31 ; 95 \%$ CI $0.17-0.45)$, peaked at week $8(0.46$; 95\% CI 0.28-0.65) and then trended downwards, with residual effects still present at week $24(0.21 ; 95 \% \text { CI } 0.10-0.31)^{20}$. By contrast, the results of the third meta-analysis from 2012 revealed that the benefits of HA for patients with symptomatic OA were minimal to non-existent and discouraged the use of HA owing to an increased risk of harm ${ }^{61}$. The apparent disconnect between the conclusions of these two studies ${ }^{61}$ is probably caused by the use of newer data, the exclusion of studies with fewer than 100 patients per treatment group and the inclusion of an additional five unpublished studies that showed that HA was not superior to placebo in the 2012 metaanalyses 61 .

Similar to the AAOS guidelines ${ }^{40}$ and the OARSI guidelines ${ }^{47}$, the NICE guidelines ${ }^{51}$ and the $\mathrm{ACR}^{52}$ guidelines ${ }^{61}$ were both less in favour of using $\mathrm{HA}$ injections than they were for glucocorticoid injections. NICE recommended against the use of HA for the management of knee $\mathrm{OA}^{51}$, a recommendation that relied on a 2006 Cochrane Database review ${ }^{62}$ and an additional 20 studies that were published between 2006 and 2014. The NICE guidelines concluded that the evidence to show that HA was clinically effective was uncertain and determined that HA was unlikely to be cost effective. Similarly, the ACR did not issue broad recommendations either for or against the use of $\mathrm{HA}$ in patients with knee $\mathrm{OA}^{52}$.

Systematic reviews published after the AAOS guidelines and OARSI guidelines (2013 and 2014, respectively) have drawn inconsistent conclusions regarding the clinical utility of HA injections. A 2015 meta-analysis of double-blinded, sham-controlled trials that had at least 60 patients found an average treatment effect that was only 29\% of the MID compared with placebo and no clinically important improvement in pain or other outcomes, even after subdividing HA preparations by molecular mass ${ }^{63}\left(\mathrm{M}_{\mathrm{r}}\right)$. By contrast, a 2018 systematic review in which non-operative treatments for knee OA were compared showed "strong evidence" for clinically important treatment effects when using intra-articular HA formulations with an $\mathrm{M}_{\mathrm{r}}$ of between 1,500 and 6,000 $\mathrm{kDa}^{64}$. Continued publication of contradictory recommendations, in conjunction with a lack of treatment consensus among clinicians, indicates that a need still exists for well-designed pragmatic trials to evaluate the real word effectiveness of intra-articular HA for OA.

\section{Intra-articular delivery of biologics}

The idea that the progression of OA could result from an imbalance of catabolic and anabolic factors, as well as the known effectiveness of biologics in the treatment of inflammatory forms of arthritis, has raised hope that biologic agents might be used to treat $\mathrm{OA}^{5}$. Over the past 10 years, several notable studies that used biologic agents have been published (Table 2), but to date, results from clinical trials have mostly been disappointing. 
In the following subsections, we discuss some of the most notable clinical studies to have used intra-articular biologic agents.

\section{Targeting IL-1}

IL- $1 \beta$ is a key mediator of the inflammatory and catabolic processes that lead to cartilage degradation and the destruction of joint tissues ${ }^{65,66}$. IL-1 $\beta$ has been used to induce the dedifferentiation of chondrocytes in vitro ${ }^{67}$, and the results of in vivo experiments suggest that IL- $1 \beta$ might directly mediate the erosive processes that lead to $\mathrm{OA}^{68-70}$. A 2009 randomized, multicentre, double-blind, placebo-controlled trial showed the IL-1 $\beta$ antagonist anakinra to be well tolerated, but not associated with improvements in OA symptoms compared with placebo ${ }^{71}$. A 2012 study in which the effects of anakinra following anterior cruciate ligament injury were examined found that patients treated with anakinra had reduced pain and improved knee function compared with the control group ${ }^{72}$.

\section{Targeting TNF}

TNF is a pro-inflammatory cytokine that interacts with chondrocytes ${ }^{73}$ and is associated with a loss of knee cartilage ${ }^{74,75}$. Infliximab was one of the first anti-TNF therapies to be clinically investigated as a potential intra-articular treatment for OA. Despite evidence of initial tolerability, development of infliximab for OA never progressed beyond early exploratory trials ${ }^{76}$. Another TNF inhibitor, etanercept, was subsequently evaluated for pain relief in patients with moderate-to-severe knee $\mathrm{OA}^{77}$. In this study, 39 patients were treated with a single intra-articular injection of either HA or etanercept and followed for 4 weeks. For patients treated with etanercept, the VAS at week 1 and week 2 was improved compared with the VAS of those treated with HA, but these differences were diminished by week $4^{77}$. Intra-articular administration of the TNF inhibitor adalimumab has also been investigated in patients with knee OA in an open-label randomized controlled trial (RCT) ${ }^{78}$. The authors of this study reported safety and improvements in VAS; however, major methodological flaws, the most notable being the failure to register the trial and to pre-specify the outcomes, limit the utility of their findings.

\section{Growth factor therapy}

Only two clinical trials in which intra-articular growth factor therapy was used to treat knee OA have been published to date. The first study, published in 2010, was a randomized, double-blind, placebo-controlled, single-dose escalation study in which the safety, tolerability and dose-limiting toxicity of recombinant human bone morphogenetic protein 7 (rhBMP7) was evaluated ${ }^{79}$. All 33 enrolled participants completed the 24-week study. There was no dose-limiting toxicity and the WOMAC scores suggested an improvement in pain, particularly in the mid-dose cohort. Although the findings of this study ${ }^{79}$ generally supported continued development of rhBMP7, no further intra-articular clinical investigations have been initiated.

The second study to use an intra-articular growth factor therapy in patients with knee OA was a randomized, double-blind, placebo-controlled, proof-of-concept trial that aimed to evaluate the safety and efficacy of recombinant human fibroblast growth factor 18 (sprifermin $)^{80}$. Single-dose and multiple-dose regimens were trialled in 180 patients, 168 of 
whom were evaluated for the primary end point of changes in cartilage thickness at 6 months and 12 months. No significant difference was seen in serious adverse events or acute inflammatory reactions between the treatment and placebo groups, and patients treated with sprifermin had statistically significant dose-dependent improvements in several secondary outcomes. Post hoc analysis from this trial and the preliminary results from the ongoing phase II trial are discussed in detail in the clinical pipeline section of this Review.

\section{Cell therapies}

\section{Autologous point-of-care cell therapies}

A lack of study comparability, as well as both methodological and intrinsic limitations, makes the efficacy of point-of-care cell therapies difficult to critically appraise. A comprehensive review of these treatments is beyond the scope of this Review; however, a basic understanding of point-of-care cell therapies is crucial given their widespread clinical use in the United States. In the following sections, we provide a general overview of the most commonly administered and/or studied point-of-care cell therapies used to treat knee OA (Figure 2).

Platelet-rich plasma.-Platelet-rich plasma (PRP) is autologous blood that has been centrifuged to concentrate the platelets to a level above that normally found in serum ${ }^{81}$; however, the term PRP has been used to describe a range of different treatments ${ }^{82}$. PRP contains a complex and diverse milieu of chemical mediators that interact with endogenous cells within the joint ${ }^{83}$. This treatment was originally cleared by the FDA for use in enhancing the handling properties of bone graft materials ${ }^{84}$ or, in the case of PRP gel, to "maintain moisture" in a wound ${ }^{85,86}$ Although intra-articular injections of PRP can be legally offered 'off-label' in the United States to patients with OA in the clinic ${ }^{87}$, they are not approved by the FDA for this indication and are not covered by most health insurance companies $^{88,89}$.

Despite being the most studied point-of-care cell therapy for OA, a lack of well-powered trials and confusion resulting from both the biological complexity and lack of standardization between different PRP protocols ${ }^{90}$ make it hard to draw conclusions about efficacy. However, several meta-analyses have attempted to broadly shed light on this topic $^{91}$. A 2013 quantitative synthesis of data from RCTs showed that patients treated with sequential intra-articular PRP injections had significant improvements in WOMAC scores at 6 months compared with those who had been treated with injections of saline or HA (mean difference $18.0 ; 95 \%$ CI 8.3 to 28.8$)^{92}$. A 2016 systematic review suggested similar improvements in WOMAC scores up to 1 year post intervention (mean difference: -15.4; $95 \% \mathrm{CI}-28.6$ to -2.3$)^{93}$. The magnitude of these differences is notable ${ }^{94-96}$, but additional standardized, high-quality studies are needed before preliminary conclusions about efficacy can be drawn.

Bone marrow aspirate concentrate.-The methods used to prepare bone marrow aspirate concentrate (BMAC) are similar to those used to prepare PRP. As such, BMAC and PRP share many of the same limitations. For example, the methods used to prepare BMAC are highly variable ${ }^{97,98}$, which limits the comparability of treatments and studies. Intra- 
articular injections of BMAC for knee OA are not covered by health insurance in the United States. As with PRP, BMAC is a source of potentially beneficial anabolic and antiinflammatory mediators ${ }^{99}$; however, extracting bone marrow is more costly and invasive than extracting peripheral blood. Moreover, BMAC injections are frequently marketed as 'stem cell' or regenerative treatments ${ }^{100}$ despite the fact that only $0.001-0.01 \%$ of the cellular content of BMAC is stromal cells ${ }^{101}$ and no clear regenerative benefits have been demonstrated to date ${ }^{97}$.

Adipose tissue injections.-Autologous adipose tissue injections (also known as fat grafts) are obtained and processed at the point-of-care from lipoaspirate by mechanical means without the use of enzymatic digestion ${ }^{102}$. In accordance with the 2015 FDA guidelines for human cells, tissues, cellular products and tissue-based products ${ }^{103}$, proponents of these treatments claim that mechanical processing of adipose tissue "does not alter the original relevant characteristics of the tissue relating to its utility for reconstruction, repair, or replacement" and that the injections merely provide cushioning and support. These 2017 claims amount to careful restatements of the 2015 FDA's criteria for 'minimal manipulation' and 'homologous use'104, which must be met for a product to be regulated solely under Section 361 of the Public Health Service Act ${ }^{105}$. Despite being widely available throughout the United States, few human studies have been conducted to date that have demonstrated the effectiveness of these 'minimally manipulated' treatments ${ }^{98}$.

Stromal vascular fraction.-Stromal vascular fraction (SVF) is treated differently than the aforementioned mechanical point-of-care cell therapies. The FDA has stated that they consider it beholden to the provisions for investigational new drugs because enzymatic digestion is needed to dissociate and isolate the stromal elements from the surrounding connective tissue ${ }^{104}$. The final cell product, which is prepared by centrifugation of the enzymatically digested tissue, is a distinct component of lipoaspirate that contains a population of progenitor cells ${ }^{106}$. However, SVF is highly heterogeneous ${ }^{107}$ and only $~ 15-$ $30 \%$ of the cellular content is stromal cells ${ }^{108}$. Moreover, although adipose-derived stromal cells can be purified from SVF ${ }^{106}$, SVF should not be confused with adipose-derived stromal cells ${ }^{102,108}$. Several Few clinical studies have been performed to investigate the use of SVF to treat cartilage pathology ${ }^{109,110}$, but the clinical use of SVF as an intra-articular agent is less common ${ }^{111}$ and the few studies that have been published have only provided preliminary safety data ${ }^{112,113}$.

\section{'Stem' or stromal cell therapies}

Mesenchymal 'stem' (or stromal) cell (MSC)-based therapies are not a homogeneous class of cellular treatments ${ }^{114}$. Because clinical trials to date have been limited to low-powered safety studies (that often did not include a control), the authors of systematic reviews that have attempted to critically appraise the use of intra-articular MSCs have failed to reach clinically applicable conclusions ${ }^{115-118}$. Nevertheless, given the increase in orthopaedic clinics marketing 'stem cell' treatments in the United States ${ }^{100}$, these therapies cannot be ignored. A comprehensive overview of studies investigating MSC injections for knee OA will not be provided here, as numerous reviews of this topic exist ${ }^{116-119}$. However, certain aspects of the field are often overlooked and require clarification (Box 1). 
Stem cells or stromal cells?-The term MSC was first coined in the early 1990s and was taken to mean mesenchymal stem cell ${ }^{120}$. Since that time a number of different definitions have been associated with the term ${ }^{121}$. The most pervasive and widely accepted definition (mesenchymal stromal cell) was established in 2006 by the International Society for Cellular Therapy (ISCT) ${ }^{122} 1$ year after they had released a position statement that attempted to retain the 'MSC' abbreviation while separating MSCs from the 'stem cell' label ${ }^{123}$. According to the ISCT criteria, MSCs must be plastic-adherent, express or lack specific cell surface markers and be capable of trilineage differentiation into osteoblasts, adipocytes and chondrocytes in vitro ${ }^{122}$.

The term mesenchymal 'stem' cell conveys assumptions that were not included in the original concept ${ }^{120}$ or supported by direct experimental evidence ${ }^{124}$. However, with respect to their clinical use as an intra-articular therapy for OA, MSCs are plastic-adherent (or prospectively isolated) populations of stromal cells that can be obtained from any tissue, and that express specific cell surface markers and are capable of trilineage differentiation in vitro $^{108,122}$. This definition clearly distinguishes MSC treatments from the various cell concentrates discussed previously without overtly conflicting with the original ISCT criteria (Figure 2).

Mechanism of action.-Although the in vivo mechanisms of therapeutically used MSCs are still unclear, the release of chemical mediators is thought to be important ${ }^{125}$. The conditions treated with MSCs fall into two broad categories: immune or inflammatory conditions and tissue repair or regeneration ${ }^{126}$. However, it is important to stress that besides in a few well-established indications, the assertion that MSCs have an intrinsic capacity to sense and address whatever is needed for the repair and regeneration of cartilaginous tissue in the joint is not based on scientific evidence ${ }^{127}$.

Are MSC therapies safe to use?-The safety profile of MSC therapies depends on the type of cell that is used, as well as the methods that are used to isolate and process it. For example, autologous cells administered at point-of-care are likely to have a lower risk of tumorigenicity than cells that have been expanded in vitro ${ }^{128}$, as culture conditions can modulate the mechanisms by which therapeutic cell products operate in vivo ${ }^{67,126}$. Although no major adverse events have been reported that were attributable to autologous or allogeneic MSCs administered via intra-articular injection ${ }^{115,117}$, malignant transformation remains a potential risk for any cell therapy. According to the results of a 2017 systematic review, over one third of studies failed to clearly describe their method of assessing safety ${ }^{129}$. Additionally, the majority of studies have focused on the use of autologous cells; only two studies have been published on intra-articular allogeneic MSC treatments for knee OA or knee cartilage repair ${ }^{130,131}$. Moreover, even in the absence of serious adverse events, the use of expensive, unproven cell therapies could delay or hinder a patient's access to wellestablished surgical treatment options ${ }^{105}$.

Clinical use of MSCs and progenitor cells.-With a few exceptions ${ }^{115,116}$, literature reviews have tended to take a positive view of MSCs as a promising potential treatment alternative for OA and cartilage repair ${ }^{117-119,132,133}$. However, an apparent disconnect exists between the results of in vitro studies, preclinical studies and human studies ${ }^{134}$, and the 
highly heterogeneous nature and poor quality of studies published to date precludes quantitative synthesis ${ }^{118}$. Moreover, among the RCTs that have been published to date, intragroup improvements and/or inter-group sub-score differences are often highlighted, whereas intra-group comparisons fail to show improvement or are left unreported. ${ }^{135}$ Overall, the limited availability of strong clinical data suggests that the generally positive efficacy conclusions concerning MSC therapy for knee cartilage pathology are premature and might be overstated. Nevertheless, broad efficacy conclusions are of little practical utility given the complexity and intrinsic lack of comparability between different MSC treatments. Just as each biologic therapy must be evaluated on a case-by-case basis, so too must each MSC therapy.

\section{The intra-articular therapy pipeline}

Several intra-articular treatments for OA are currently in clinical development (Figure 3). In the following section, we discuss some of the most anticipated and promising of these treatments and critically appraise the data that is currently available. Therapies in this section have all had clinical data published or presented and are progressing towards FDA approval. As such, promising therapeutic candidates that are currently in early-clinical or preclinical development, such as RCGD $423^{136}$ and UBX0 101 ${ }^{137,138}$, are not discussed. Treatments for which clinical data has been published, but for which there are no current plans for further development, such as co-injected Tr14 (Traumeel) and Ze14 (Zeel) ${ }^{139}$ have also been excluded from this Review.

One of the notable intra-articular therapies that is not included in the discussion below is AmnioFix, a mixture containing human amniotic and chorionic membranes that have been dehydrated, micronized and suspended in saline ${ }^{140,141}$. This treatment deserves mention because, prior to 2013, a number of clinics in the United States were using AmnioFix to treat knee OA under the assumption that the treatment was 'minimally manipulated'. However, MiMedx (the company that produces AmnioFix) was forced to recant their claims when the FDA warned that the treatment could not be offered to patients until an investigational new drug (IND) application was obtained. In 2017, MiMedx reported that the FDA had allowed their IND-approved, phase-IIb study ${ }^{142}$ to proceed. However, no clinical data has been released and only one animal study investigating the effects of AmnioFix for knee cartilage pathology has been published ${ }^{143}$.

\section{LMWF-5A (Ampion)}

LMWF-5A (Ampion) is an injectable, low molecular weight fraction of 5\% human serum albumin that is currently being developed by Ampio Pharmaceuticals (Englewood, FL, USA). The primary constituent of LMWF-5A, artyl-alanyl diketopiperazine, modulated the inflammatory immune response in vitro through a pathway in which $\mathrm{T}$ cells were implicated ${ }^{144}$, and several clinical studies have been published in which the effects of LMWF-5A on knee OA were investigated ${ }^{145-147}$.

To date, the most notable study ${ }^{145}$ to investigate the use of LMWF-5A to treat knee OA was published in 2014. In this study, 329 patients were randomized at a ratio of 1:1:1:1 to receive a single $4 \mathrm{ml}$ or $10 \mathrm{ml}$ intra-articular injection of either LMWF-5A or saline. The WOMAC 
pain scores of patients treated with LMWF-5A were significantly better than those treated with placebo at week 12 (estimated difference from control $-0.25, P=0.004)^{145}$. However, the effect size was roughly one quarter of what was assumed, and such a small difference is not likely to be clinically meaningful to an appreciable numberof patients ${ }^{31}$. Nevertheless, Ampio Pharmaceuticals announced that their phase III clinical trial met its primary endpoint, with $71 \%$ of patients in the treatment group meeting the Outcome Measures in Rheumatology (OMERACT)-OARSI responder criteria. Overall, the available data suggests that the shortterm effects of LMWF-5A may be non-inferior (although not likely to be superior) to currently used intra-articular treatment modalities. The long-term effects of LMWF-5A have yet to be determined, but the results of in vitro studies ${ }^{144,148}$ and of a post hoc analysis ${ }^{147}$ are encouraging. An open label, phase III extension study to evaluate the long-term safety of LMWF-5A is currently underway ${ }^{149}$.

\section{HA-triamcinolone hexacetonide (Cingal)}

Cingal is an HA-triamcinolone hexacetonide combination drug that was developed by Anika Therapeutics, Inc. (Bedford, MA, USA). A 2017 double-blind, saline-controlled trial compared the use of Cingal, HA (the same as that used in Cingal) and saline in 149, 150 and 69 patients with knee OA, respectively ${ }^{150}$. In this study, Cingal provided better symptomatic relief than placebo, as measured by the WOMAC pain score at 26 weeks. However, Cingal only produced statistically significant benefits at week- 1 and week- 3 when compared with HA alone. Although the authors of this study ${ }^{150}$ claim that the rapid response seen in patients demonstrates Cingal's "clinical significance", the report does not mention the MID and the short-term improvements compared with HA alone were modest $(<10 \%$ difference $)^{150}$. A single-group follow-on study in which the safety of repeated Cingal injections was investigated was completed in 2015, but the results have yet to be announced or published ${ }^{151}$. Overall, the currently available data does not support the use of Cingal over HA, although the results from an ongoing phase III trial $(n=576)$ in which Cingal is compared with HA alone and triamcinolone hexacetonide alone ${ }^{152}$ are needed before firm efficacy conclusions can be drawn.

\section{Autologous protein solution}

The nSTRIDE APS kit (Zimmer Biomet, Warsaw, IN, USA) is a single-use device that produces a 'cell concentrate' from autologous blood (Figure 2), which the manufacturer refers to as an autologous protein solution (APS). Conceptually, APS and PRP containing white blood cells are very similar. However, unlike traditional PRP systems, the nSTRIDE APS kit passes the concentrated plasma though a dried polyacrylamide gel that preferentially concentrates anti-inflammatory cytokines including IL-1 receptor antagonist and TNF receptor inhibitor ${ }^{153}$. Zimmer Biomet have also obtained an Investigational Device Exemption (IDE) for the nSTRIDE APS kit ${ }^{154}$, which means that, unlike PRP, if approved, the intra-articular administration of APS to patients with OA would not be considered offlabel use.

APS has demonstrated preliminary feasibility in preclinical models ${ }^{155,156}$ and safety in patients with $\mathrm{OA}^{154,157}$. The results of the phase II trial ${ }^{158}$ showed a statistically significant improvement in WOMAC pain score at 12 months for APS compared with placebo, which

Nat Rev Rheumatol. Author manuscript; available in PMC 2019 August 01. 
the authors claim became apparent between 6 and 12 months. However, in this study ${ }^{158}$, outcomes were not assessed between 6 and 12 months, the WOMAC was not a pre-specified outcome of interest and no statistically significant differences between the WOMAC pain scores for APS and placebo at week 2, month 1, month 3 and month 6 were found. Additionally, the authors of the study failed to report that the primary outcome (VAS at month 6) was not met and that statistically significant differences were not found in the responder rate, VAS, quality-of-life, patient/clinical global impression of change or KOOS at any time point ${ }^{159}$. Nevertheless, the generally positive safety profile of APS supports continued clinical development and the results from an ongoing phase III clinical trial $(\mathrm{n}=246)$ in which the nSTRIDE APS kit is compared with saline ${ }^{160}$ are needed before preliminary efficacy conclusions can be drawn.

\section{SM04690}

SM04690 is a novel small molecule Wnt- $\beta$-catenin signalling pathway inhibitor that is currently being developed by Samumed LLC (San Diego, CA, USA) ${ }^{161}$. Excessive activation of $\beta$-catenin-dependent signalling pathways can severely inhibit cartilage formation, as well as growth plate organization and function ${ }^{162}$. Additionally, inhibition of $\beta$-catenin-dependent signalling pathways induces chondrogenesis and inhibits joint destruction in rats ${ }^{163}$.

The exact mechanism of action of SM04690 is still under investigation ${ }^{161}$, and previous attempts using mice to inhibit Wnt signalling pathways have failed ${ }^{164,165}$. Nevertheless, the results from the first-inhuman, 24-week, phase I RCT revealed SM04690 to be safe and well-tolerated and showed no evidence of exposure outside of the injected joint ${ }^{166}$. Additionally, all three treatment cohorts had reduced joint space narrowing compared with the placebo group at 24 weeks. A phase IIb study to evaluate the safety and efficacy of SM04690 is ongoing ${ }^{167}$, but a phase IIa trial ${ }^{168}$ in which $0.03 \mathrm{mg}, 0.07 \mathrm{mg}$ and $0.23 \mathrm{mg}$ doses of SM04690 were compared with placebo was completed in $2017(\mathrm{n}=455)$. Results from this trial ${ }^{168}$ have yet to be formally published, but preliminary findings have been announced. The improvements in clinical outcomes and JSW in the intention-to-treat population were not statistically significant, but the subpopulation of unilateral symptomatic patients in the mid-dose cohort demonstrated better improvements in WOMAC and medial JSW than patients in the control group at week-52. This subpopulation was not a prespecified group of interest for this trial ${ }^{168}$, but unilateral symptomatic patients are listed as a subgroup of interest in the ongoing phase IIb trial ${ }^{167}$.

\section{rhFGF18 (sprifermin)}

Human recombinant fibroblast growth factor 18 (sprifermin) is a growth factor therapy being developed by EMD Serono (Darmstadt, Germany and Billerica, MA, USA). As mentioned in the section on growth factor therapy, the largely successful phase I trial showed preliminary safety and efficacy ${ }^{80}$. Post hoc analyses of the phase I data showed slight improvements in cartilage at the patellofemoral joint ${ }^{169}$, as well as a minor increase in cartilage thickness and a small reduction in cartilage $\operatorname{loss}^{170}$. A 5-year randomized, placebocontrolled, phase-II study in which 3 weekly intra-articular injections of placebo or sprifermin administered in cycles of once every 6 months or once every 12 months are 
compared ( $\mathrm{n}=549)$ is currently in its final year ${ }^{171}$. In the 2-year results, which were reported at the ACR annual meeting in 2017, the primary endpoint of a change in total tibiofemoral joint cartilage thickness from baseline was met ${ }^{172}$. Patients that were treated with $100 \mu \mathrm{g}$ of sprifermin every 6 months or every 12 months had a significantly greater increase in total tibiofemoral joint cartilage thickness than patients in the control group $(+0.03 \mathrm{~mm}$ and $+0.02 \mathrm{~mm}$ versus $-0.02 \mathrm{~mm}$, respectively; $P<0.001)^{172}$. Although clinical outcome data showing improvements in pain and function compared with placebo is still needed to validate the utility of the reported structural modifications, the data released to date seem to suggest a disease-modifying benefit.

\section{CNTX-4975}

CNTX-4975 is an injectable, high-purity trans-capsaicin that is currently being developed by Centrexion Therapeutics (Boston, MA, USA). This treatment targets the capsaicin receptor (TRPV1), which contributes to the detection and integration of pain-producing stimuli ${ }^{173}$. The analgesic effects of capsaicin-based treatments have been attributed to several different mechanisms (collectively referred to as the 'defunctionalization' of nociceptive fibres), including the transient retraction of nerve fibre terminals ${ }^{174,175}$. Before the technology was acquired by Centrexion Therapeutics, a less purified version of CNTX-4975 (ALRGX-4975) was clinically investigated by Anesiva Inc. as a treatment for postoperative pain under the name Adlea ${ }^{176}$. The results of the studies conducted by Anesiva Inc. were never published or released, and it was not until Centrexion Therapeutics acquired the technology that the treatment was first administered via intra-articular injection to treat moderate-to-severe OArelated pain.

The results of the phase IIb study in which CNTX-4975 was compared with placebo were reported at meetings in 2017177,178. Patients treated with 1mg CNTX-4975 ( $\mathrm{n}=70)$ had improved WOMAC A1 scores (10 point VAS) at week-12 (LSMD -1.6) and at week-24 (LSMD -1.35) compared with patients who received placebo $(n=69)$. With respect to intraarticular therapies currently in clinical use, the magnitude of difference and duration of benefits for CNTX-4975 is very encouraging, particularly given the inclusion of morbidly obese patients and patients with severe OA (Kellgren-Lawrence grade II-grade IV). The most notable limitation of CNTX-4975 is that it does not halt or reverse the course of OA pathogenesis. Clinical data has been presented at a number of scientific congresses, but the preliminary mechanistic data has yet to be published. Nevertheless, Centrexion Therapeutics has begun recruiting participants for a phase III trial $(n=325)^{179}$, and this treatment was granted Fast Track designation by the FDA in 2018.

\section{TissueGene C (Invossa)}

TissueGene $\mathrm{C}$ is a cell therapy being developed by Kolon Tissue Gene, Inc. (Rockville, MD, USA). The therapy, which is currently available in South Korea under the trade name Invossa, is a mixture containing chondrocytes that have been transduced with a viral vector containing $T G F B 1$. In preclinical studies, the genetically modified chondrocytes demonstrated long-term transforming growth factor- $\beta$ secretion and constitutive type II collagen expression in vitro, as well as the ability to form cartilage in vivo ${ }^{180}$. Following the successful completion of a phase I safety study ${ }^{181}$, a phase-II, multi-centre, double-blinded, 
placebo-controlled RCT in which TissueGene $C(n=67)$ is compared with saline $(n=35)$ was conducted ${ }^{182}$. Although no difference was found between TissueGene $\mathrm{C}$ and saline in the International Knee Documentation Committee (IKDC) or VAS scores of patients at week-4 or week-24, statistically significant differences between the groups were observed at week-12, week-52 and overall ${ }^{182}$. The magnitude of the overall difference was notable, particularly for a phase II trial. However, the analysis was not intent-to-treat and 16 patients $(24.2 \%)$ in the treatment group and 6 patients $(18.8 \%)$ in the control group were lost to follow-up, which could have introduced selection bias. A 2017 publication in which the structural effects of TissueGene $\mathrm{C}$ were detailed provided unclear evidence of disease modification $^{183}$.

Data from a multi-centre, double-blind, clinical trial conducted in South Korea revealed that TissueGene $\mathrm{C}$ provided long-term clinical benefits compared with placebo ${ }^{184}$. In this study, 163 patients with Kellgren-Lawrence grade III OA were randomly assigned to receive a single intra-articular injection of TissueGene $\mathrm{C}$ or saline. The study met both of its primary outcomes of showing statistically significant improvements in IKDC ( +15 versus $+5 ; P<$ $0.001)$ and VAS ( -25 points versus -10 points; $P<0.001$ ) scores at 52 weeks compared with control ${ }^{184}$. The IKDC and VAS scores were also improved at week-26 and week-39, and statistically significant improvements were seen in secondary clinical outcomes (WOMAC and KOOS) at week-52 compared with control. Although significant differences on radiographs (changes in JSW) or whole-organ MRI scoring were not observed, post hoc analysis of MRI data suggested possible (albeit small) improvements in cartilage thickness. ${ }^{183}$ Even in the absence of disease modification, the relatively robust and consistent longterm improvements of patients treated with TissueGene $\mathrm{C}$ across different clinical outcomes is promising. A follow-up phase III study ( $\mathrm{n}=510$ ) has been announced ${ }^{185}$ and powered to determine if the treatment provides a disease-modifying effect.

\section{FX006 (Zilretta)}

FX006 (Zilretta) is an intra-articular microsphere-based formulation of triamcinolone acetonide developed by Flexion Therapeutics (Burlington, MA, USA) that has been approved by the FDA for use in treating OA-related knee pain. This extended-release glucocorticoid uses a proprietary matrix that is designed to prolong the analgesic benefits of triamcinolone acetonide in patients with knee $\mathrm{OA}^{186}$. A phase IIa trial in which FX006 was compared with triamcinolone acetonide failed to show a statistically significant improvement in pain from baseline at 12 weeks, but did demonstrate significant improvements at 8 weeks and 10 weeks ${ }^{187}$ (all three time points were pre-specified as the primary outcomes ${ }^{188}$ ). The promising results of this trial prompted a follow-up phase IIb trial to compare $32 \mathrm{mg}$ FX006 $(\mathrm{n}=104), 16 \mathrm{mg}$ FX006 $(\mathrm{n}=102)$ and saline $(\mathrm{n}=100)^{189}$. Similar to the phase IIa trial, the follow-up phase IIb trial failed to show statistically significant improvements in average daily pain (ADP) at 12 weeks compared with saline (primary outcome), but did show a statistically significant difference in ADP between FX006 and saline at weeks 1-11 and at week-13 (secondary outcomes) ${ }^{189}$.

In a 24-week, phase III, multi-centre, double-blinded RCT, patients with knee OA were treated with a single intra-articular injection of FX006 $(n=161)$, placebo $(n=162)$ or 
triamcinolone acetonide $(\mathrm{n}=161)^{190}$. Although patients treated with FX006 had a greater improvement in the ADP at week-12 than those treated with placebo(-3.12 versus -2.14$)$, an improvement in ADP compared with patients treated with triamcinolone acetonide was not seen ${ }^{190}$. The failure to find a statistically significant difference between triamcinolone acetonide and FX006 might have resulted from the large assumed effect size, which was considerably larger than can be justified by the results of the phase IIb study ${ }^{189}$. Moreover, although statistically significant improvements were seen in several exploratory endpoints (such as WOMAC subscales and KOOS quality of life) compared with triamcinolone acetonide, the differences were very small and not likely to be clinically significant.

Overall, FX006 seems to provide better pain relief than intra-articular saline; however, the advantages over traditional formulations of triamcinolone acetonide are unclear. Although it is possible that FX006 provides better pain relief than traditional triamcinolone acetonide formulations, particularly short-term ( $<12$ weeks), additional appropriately powered studies that compare traditional triamcinolone acetonide formulations and FX006 are still needed, and it seems unlikely likely that the magnitude of the difference would be large enough to be clinically important to an appreciable number of patients. Given the lack of long-term data, the potentially harmful long-term effects of glucocorticoids and the questionable clinical benefits of FX006 compared with traditional triamcinolone acetonide, clinicians should be particularly careful when prescribing FX006.

\section{Conclusions}

For most of the 21st century, HA and glucocorticoids have been the standard treatments for the management of knee OA in patients who fail to respond to non-pharmacologic therapy, NSAIDs or analgesics. Although the prospect of new, non-surgical treatments for knee OA is likely to cause excitement in both clinicians and their patients, the benefits of new treatments must be carefully weighed against their cost and potential risks. It should be remembered that a strong placebo response exists to agents administered via intra-articular injection and that new intra-articular treatments might not be appropriate for every patient.

\section{Acknowledgements}

The work of the authors was supported by grants UL1TR001855 and UL1TR000130 from the National Center for Advancing Translational Science (NCATS) of the U.S. National Institutes of Health. The content is solely the responsibility of the authors and does not necessarily represent the official views of the National Institutes of Health.

\section{References}

1. Sinusas K Osteoarthritis: diagnosis and treatment. Am Fam Physician (2012).

2. Liu-Bryan R Synovium and the innate inflammatory network in osteoarthritis progression. Curr Rheumatol Rep 15, 323 (2013). [PubMed: 23516014]

3. Haseeb A \& Haqqi TM Immunopathogenesis of osteoarthritis. Clin. Immunol 146, 185-196 (2013). [PubMed: 23360836]

4. Aigner T, Söder S, Gebhard PM, McAlinden A \& Haag J Mechanisms of disease: role of chondrocytes in the pathogenesis of osteoarthritis--structure, chaos and senescence. Nature clinical practice. Rheumatology 3, 391-399 (2007). [PubMed: 17599073] 
5. Chevalier X, Eymard F \& Richette P Biologic agents in osteoarthritis: hopes and disappointments. Nature Reviews Rheumatology 9, 400-410 (2013). [PubMed: 23545735]

6. Lories RJ \& Luyten FP The bone-cartilage unit in osteoarthritis. Nature Reviews Rheumatology 7 , 43-49 (2011). [PubMed: 21135881]

7. Emami A et al. Toxicology Evaluation of Drugs Administered via Uncommon Routes: Intranasal, Intraocular, Intrathecal/Intraspinal, and Intra-Articular. Int. J Toxicol 37, 4-27 (2018). [PubMed: 29264927]

8. Evans CH, Kraus VB \& Setton LA Progress in intra-articular therapy. Nature Reviews Rheumatology 10, 11-22 (2014). [PubMed: 24189839]

9. Rousseau J-C \& Delmas PD Biological markers in osteoarthritis. Nature clinical practice. Rheumatology 3, 346-356 (2007). [PubMed: 17538566]

10. Robinson WH et al. Low-grade inflammation as a key mediator of the pathogenesis of osteoarthritis. Nature Reviews Rheumatology 12, 580-592 (2016). [PubMed: 27539668]

11. Sellam J \& Berenbaum F The role of synovitis in pathophysiology and clinical symptoms of osteoarthritis. Nature Reviews Rheumatology 6, 625-635 (2010). [PubMed: 20924410]

12. Maudens $\mathrm{P}$, Jordan $\mathrm{O} \&$ Allémann E Recent advances in intra-articular drug delivery systems for osteoarthritis therapy. Drug Discov. Today(2018). doi:10.1016/j.drudis.2018.05.023

13. Miller RE, Block JA \& Malfait A-M What is new in pain modification in osteoarthritis? Rheumatology (Oxford) 58, 26 (2018).

14. Nelson AE, Allen KD, Golightly YM, Goode AP \& Jordan JM A systematic review of recommendations and guidelines for the management of osteoarthritis: The chronic osteoarthritis management initiative of the U.S. bone and joint initiative. Semin. Arthritis Rheum 43, 701-712 (2014). [PubMed: 24387819]

15. Nguyen C, Lefèvre-Colau M-M, Poiraudeau S \& Rannou F Evidence and recommendations for use of intra-articular injections for knee osteoarthritis. Ann Phys Rehabil Med 59, 184-189 (2016). [PubMed: 27103055]

16. Gerwin N, Hops C \& Lucke A Intra-articular drug delivery in osteoarthritis. Advanced Drug Delivery Reviews 58, 226-242 (2006). [PubMed: 16574267]

17. Habib GS Systemic effects of intra-articular corticosteroids. Clin. Rheumatol 28, 749-756 (2009). [PubMed: 19252817]

18. Jackson DW, Evans NA \& Thomas BM Accuracy of needle placement into the intra-articular space of the knee. The Journal of Bone \& Joint Surgery 84-A, 1522-1527 (2002). [PubMed: 12208907]

19. Larsen $\mathrm{C}$ et al. Intra-articular depot formulation principles: role in the management of postoperative pain and arthritic disorders. J Pharm Sci 97, 4622-4654 (2008). [PubMed: 18306275]

20. Bannuru RR, Natov NS, Dasi UR, Schmid CH \& McAlindon TE Therapeutic trajectory following intra-articular hyaluronic acid injection in knee osteoarthritis--meta-analysis. Osteoarthr. Cartil 19, 611-619 (2011). [PubMed: 21443958]

21. Rosseland LA, Helgesen KG, Breivik H \& Stubhaug A Moderate-to-Severe Pain After Knee Arthroscopy Is Relieved by Intra-articular Saline: A Randomized Controlled Trial. Anesth. Analg 98, 1546-1551 (2004). [PubMed: 15155303]

22. Abhishek A \& Doherty M Mechanisms of the placebo response in pain in osteoarthritis. Osteoarthr. Cartil 21, 1229-1235 (2013). [PubMed: 23973135]

23. Bannuru RR et al. Effectiveness and Implications of Alternative Placebo Treatments: A Systematic Review and Network Meta-analysis of Osteoarthritis Trials. Ann Intern Med 163, 365-372 (2015). [PubMed: 26215539]

24. Kirwan JR \& Rankin E Intra-articular therapy in osteoarthritis. Baillieres Clin Rheumatol 11, 769 794 (1997). [PubMed: 9429736]

25. Hameed F \& Ihm J Injectable medications for osteoarthritis. PM R 4, S75-81 (2012). [PubMed: 22632706]

26. Saltzman BM et al. The Therapeutic Effect of Intra-articular Normal Saline Injections for Knee Osteoarthritis: A Meta-analysis of Evidence Level 1 Studies. The American Journal of Sports Medicine 45, 2647-2653 (2017). [PubMed: 28027657] 
27. Jaeschke R, Singer J \& Guyatt GH Measurement of health status: Ascertaining the minimal clinically important difference. Controlled Clinical Trials 10, 407-415 (1989). [PubMed: 2691207]

28. Redelmeier DA \& Lorig K Assessing the clinical importance of symptomatic improvements. An illustration in rheumatology. Arch. Intern. Med 153, 1337-1342 (1993). [PubMed: 8507124]

29. Angst F, Aeschlimann A \& Angst J The minimal clinically important difference raised the significance of outcome effects above the statistical level, with methodological implications for future studies. J Clin Epidemiol 82, 128-136 (2017). [PubMed: 27986610]

30. McGlothlin AE \& Lewis RJ Minimal clinically important difference: defining what really matters to patients. JAMA 312, 1342-1343 (2014). [PubMed: 25268441]

31. Devji $\mathrm{T}$ et al. Application of minimal important differences in degenerative knee disease outcomes: a systematic review and case study to inform BMJ Rapid Recommendations. BMJ Open 7, e015587 (2017).

32. Dworkin RH et al. Interpreting the clinical importance of treatment outcomes in chronic pain clinical trials: IMMPACT recommendations. in 9, 105-121 (2008).

33. Copay AG, Subach BR, Glassman SD, Polly DW \& Schuler TC Understanding the minimum clinically important difference: a review of concepts and methods. Spine J 7, 541-546 (2007). [PubMed: 17448732]

34. King MT A point of minimal important difference (MID): a critique of terminology and methods. Expert Rev Pharmacoecon Outcomes Res 11, 171-184 (2011). [PubMed: 21476819]

35. Wright A, Hannon J, Hegedus EJ \& Kavchak AE Clinimetrics corner: a closer look at the minimal clinically important difference (MCID). J Man Manip Ther 20, 160-166 (2012). [PubMed: 23904756]

36. Cook CE Clinimetrics Corner: The Minimal Clinically Important Change Score (MCID): A Necessary Pretense. J Man Manip Ther 16, E82-3 (2008). [PubMed: 19771185]

37. Revicki D, Hays RD, Cella D \& Sloan J Recommended methods for determining responsiveness and minimally important differences for patient-reported outcomes. J Clin Epidemiol 61, 102-109 (2008). [PubMed: 18177782]

38. Bedard NA et al. Impact of Clinical Practice Guidelines on Use of Intra-Articular Hyaluronic Acid and Corticosteroid Injections for Knee Osteoarthritis. J Bone Joint Surg Am 100, 827-834 (2018). [PubMed: 29762277]

39. Migliore A et al. The discrepancy between recommendations and clinical practice for viscosupplementation in osteoarthritis: mind the gap! Eur Rev Med Pharmacol Sci 19, 1124-1129 (2015). [PubMed: 25912569]

40. Jevsevar DS et al. The American Academy of Orthopaedic Surgeons evidence-based guideline on: treatment of osteoarthritis of the knee, 2nd edition. Journal of Bone and Joint Surgery-American Volume 95, 1885-1886 (2013).

41. Chao J et al. Inflammatory characteristics on ultrasound predict poorer longterm response to intraarticular corticosteroid injections in knee osteoarthritis. The Journal of Rheumatology 37, 650-655 (2010). [PubMed: 20080918]

42. Gaffney K, Ledingham J \& Perry JD Intra-articular triamcinolone hexacetonide in knee osteoarthritis: factors influencing the clinical response. Ann. Rheum. Dis 54, 379-381 (1995). [PubMed: 7794044]

43. Raynauld J-P et al. Safety and efficacy of long-term intra-articular steroid injections in osteoarthritis of the knee: a randomized, double-blind, placebo-controlled trial. Arthritis \& Rheumatism 48, 370-377 (2003). [PubMed: 12571845]

44. Jones A \& Doherty M Intra-articular corticosteroids are effective in osteoarthritis but there are no clinical predictors of response. Ann. Rheum. Dis 55, 829-832 (1996). [PubMed: 8976640]

45. Caborn D et al. A randomized, single-blind comparison of the efficacy and tolerability of hylan GF 20 and triamcinolone hexacetonide in patients with osteoarthritis of the knee. The Journal of Rheumatology 31, 333-343 (2004). [PubMed: 14760806]

46. Arden NK et al. A randomised controlled trial of tidal irrigation vs corticosteroid injection in knee osteoarthritis: the KIVIS Study. Osteoarthr. Cartil 16, 733-739 (2008). [PubMed: 18077189]

47. McAlindon TE et al. OARSI guidelines for the non-surgical management of knee osteoarthritis. Osteoarthritis and cartilage/OARS, Osteoarthritis Research Society 22, 363-388 (2014). 
48. Bannuru RR et al. Therapeutic trajectory of hyaluronic acid versus corticosteroids in the treatment of knee osteoarthritis: a systematic review and meta-analysis. Arthritis \& Rheumatism 61, 17041711 (2009). [PubMed: 19950318]

49. Bellamy $\mathrm{N}$ et al. Intra-articular corticosteroid for treatment of osteoarthritis of the knee. Cochrane Database Syst Rev 21, CD005328 (2006).

50. Jüni P et al. Intra-articular corticosteroid for knee osteoarthritis. Cochrane Database Syst Rev CD005328 (2015). doi:10.1002/14651858.CD005328.pub3 [PubMed: 26490760]

51. National Clinical Guideline Centre (UK). Osteoarthritis: Care and Management in Adults. (2014).

52. Hochberg MC et al. American College of Rheumatology 2012 recommendations for the use of nonpharmacologic and pharmacologic therapies in osteoarthritis of the hand, hip, and knee. in 64, 465-474 (2012).

53. Wernecke C, Braun HJ \& Dragoo JL The Effect of Intra-articular Corticosteroids on Articular Cartilage: A Systematic Review. Orthop J Sports Med 3, 2325967115581163 (2015). [PubMed: 26674652]

54. Bedard NA et al. The John N. Insall Award: Do Intra-articular Injections Increase the Risk of Infection After TKA? Clin. Orthop. Relat. Res 475, 45-52 (2017). [PubMed: 26970991]

55. McAlindon TE et al. Effect of Intra-articular Triamcinolone vs Saline on Knee Cartilage Volume and Pain in Patients With Knee Osteoarthritis: A Randomized Clinical Trial. JAMA 317, 19671975 (2017). [PubMed: 28510679]

56. Cicuttini FM, Jones G, Forbes A \& Wluka AE Rate of cartilage loss at two years predicts subsequent total knee arthroplasty: a prospective study. Ann. Rheum. Dis 63, 1124-1127 (2004). [PubMed: 15115714]

57. Hitzl W et al. Greater Lateral Femorotibial Cartilage Loss in Osteoarthritis Initiative Participants With Incident Total Knee Arthroplasty: A Prospective Cohort Study. Arthritis Care \& Research 67, 1481-1486 (2015). [PubMed: 25939334]

58. Bannuru RR, Vaysbrot EE \& McIntyre LF Did the American Academy of Orthopaedic Surgeons osteoarthritis guidelines miss the mark? Arthroscopy 30, 86-89 (2014). [PubMed: 24384274]

59. Carlson VR et al. Compliance With the AAOS Guidelines for Treatment of Osteoarthritis of the Knee: A Survey of the American Association of Hip and Knee Surgeons. J Am Acad Orthop Surg 26, 103-107 (2018). [PubMed: 29283898]

60. Jevsevar DS et al. Mixed Treatment Comparisons for Nonsurgical Treatment of Knee Osteoarthritis: A Network Meta-analysis. J Am Acad Orthop Surg26, 325-336 (2018). [PubMed: 29688920]

61. Rutjes AWS et al. Viscosupplementation for osteoarthritis of the knee: a systematic review and meta-analysis. Ann Intern Med 157, 180-191 (2012). [PubMed: 22868835]

62. Bellamy $\mathrm{N}$ et al. Viscosupplementation for the treatment of osteoarthritis of the knee. Cochrane Database Syst Rev 3, CD005321 (2006).

63. Jevsevar D, Donnelly P, Brown GA \& Cummins DS Viscosupplementation for Osteoarthritis of the Knee: A Systematic Review of the Evidence. J Bone Joint Surg Am 97, 2047-2060 (2015). [PubMed: 26677239]

64. Vannabouathong C et al. Nonoperative Treatments for Knee Osteoarthritis: An Evaluation of Treatment Characteristics and the Intra-Articular Placebo Effect: A Systematic Review. JBJS Rev 6, e5 (2018).

65. Kapoor M, Martel-Pelletier J, Lajeunesse D, Pelletier J-P \& Fahmi H Role of proinflammatory cytokines in the pathophysiology of osteoarthritis. Nature Reviews Rheumatology 7, 33-42 (2011). [PubMed: 21119608]

66. Martel-Pelletier J Pathophysiology of osteoarthritis. Osteoarthr. Cartil 6, 374-376 (1998). [PubMed: 10343769]

67. Ashraf $\mathrm{S}$ et al. Regulation of senescence associated signaling mechanisms in chondrocytes for cartilage tissue regeneration. Osteoarthr. Cartil 24, 196-205 (2016). [PubMed: 26190795]

68. Pettipher ER, Higgs GA \& Henderson B Interleukin 1 induces leukocyte infiltration and cartilage proteoglycan degradation in the synovial joint. Proc. Natl. Acad. Sci. U.S.A 83, 8749-8753 (1986). [PubMed: 3490671] 
69. Kato $\mathrm{T}$ et al. Exosomes from IL-1 $\beta$ stimulated synovial fibroblasts induce osteoarthritic changes in articular chondrocytes. Arthritis Res. Ther 16, R163 (2014). [PubMed: 25092378]

70. Jacques C, Gosset M, Berenbaum F \& Gabay C The role of IL-1 and IL-1Ra in joint inflammation and cartilage degradation. Vitam. Horm 74, 371-403 (2006). [PubMed: 17027524]

71. Chevalier $X$ et al. Intra-articular injection of anakinra in osteoarthritis of the knee: a multicenter, randomized, double-blind, placebo-controlled study. Arthritis \& Rheumatism 61, 344-352 (2009). [PubMed: 19248129]

72. Kraus VB et al. Effects of intra-articular IL1-Ra for acute anterior cruciate ligament knee injury: a randomized controlled pilot trial (NCT00332254). Osteoarthr. Cartil 20, 271-278 (2012). [PubMed: 22273632]

73. Goldring SR \& Goldring MB The role of cytokines in cartilage matrix degeneration in osteoarthritis. Clin. Orthop. Relat. Res S27-36 (2004). [PubMed: 15480070]

74. Stannus $\mathrm{O}$ et al. Circulating levels of IL-6 and TNF-\&alpha; are associated with knee radiographic osteoarthritis and knee cartilage loss in older adults. Osteoarthritis and Cartilage 18, 1441-1447 (2010). [PubMed: 20816981]

75. Malfait AM et al. Intra-articular injection of tumor necrosis factor-alpha in the rat: an acute and reversible in vivo model of cartilage proteoglycan degradation. Osteoarthr. Cartil 17, 627-635 (2009). [PubMed: 19026578]

76. Lindsley HB et al. FRI0304 Treatment of knee osteoarthritis with intra-articular infliximab improves total womac score. High baseline levels of synovial cellularity predict improvement. Ann. Rheum. Dis 71, 4171-417 (2014).

77. Ohtori S et al. Efficacy of Direct Injection of Etanercept into Knee Joints for Pain in Moderate and Severe Knee Osteoarthritis. Yonsei Med. J 56, 1379 (2015). [PubMed: 26256983]

78. Wang J Efficacy and safety of adalimumab by intra-articular injection for moderate to severe knee osteoarthritis: An open-label randomized controlled trial. J Int. Med. Res 46, 326-334 (2018). [PubMed: 28840750]

79. Hunter DJ et al. Phase 1 safety and tolerability study of BMP-7 in symptomatic knee osteoarthritis. BMC Musculoskeletal Disorders 11, 232 (2010). [PubMed: 20932341]

80. Lohmander LS et al. Intra-articular sprifermin (recombinant human fibroblast growth factor 18) in knee osteoarthritis: a randomized, double-blind, placebo-controlled trial. Arthritis Rheumatol 66, 1820-1831 (2014). [PubMed: 24740822]

81. Hall MP, Band PA, Meislin RJ, Jazrawi LM \& Cardone DA Platelet-rich plasma: current concepts and application in sports medicine. J Am Acad Orthop Surg 17, 602-608 (2009). [PubMed: 19794217]

82. Hsu WK et al. Platelet-rich Plasma in Orthopaedic Applications: Evidence-based Recommendations for Treatment. J Am Acad Orthop Surg 21, 739-471 (2013). [PubMed: 24292930]

83. Andia I \& Maffulli N Platelet-rich plasma for managing pain and inflammation in osteoarthritis. Nature Reviews Rheumatology 9, 721-730 (2013). [PubMed: 24080861]

84. Gutman SI 510(k) SUMMARY. (The United States Department of Health and Human Services, 2000).

85. Jones IA, Togashi RC \& Thomas Vangsness C The Economics and Regulation of PRP in the Evolving Field of Orthopedic Biologics. Curr Rev Musculoskelet Med 17, 602-8 (2018).

86. Melkerson MN 510(k)SUMMARY. (The United States Department of Health and Human Services, 2009).

87. Vaught MS \& Cole BJ Coding and Reimbursement Issues for Platelet-Rich Plasma. Operative Techniques in Sports Medicine 19, 185-189 (2011).

88. Dhillon RS, Schwarz EM \& Maloney MD Platelet-rich plasma therapy - future or trend? Arthritis Res. Ther 14, 219 (2012). [PubMed: 22894643]

89. Beitzel $\mathrm{K}$ et al. US definitions, current use, and FDA stance on use of platelet-rich plasma in sports medicine. J Knee Surg 28, 29-34 (2015). [PubMed: 25268794]

90. Chahla J et al. A Call for Standardization in Platelet-Rich Plasma Preparation Protocols and Composition Reporting: A Systematic Review of the Clinical Orthopaedic Literature. J Bone Joint Surg Am 99, 1769-1779 (2017). [PubMed: 29040132] 
91. Chen X, Jones IA, Park C \& Vangsness CT The Efficacy of Platelet-Rich Plasma on Tendon and Ligament Healing: A Systematic Review and Meta-analysis With Bias Assessment. The American Journal of Sports Medicine 2016, 363546517743746 (2017).

92. Khoshbin A et al. The efficacy of platelet-rich plasma in the treatment of symptomatic knee osteoarthritis: a systematic review with quantitative synthesis. Arthroscopy 29, 2037-2048 (2013). [PubMed: 24286802]

93. Kanchanatawan $\mathrm{W}$ et al. Short-term outcomes of platelet-rich plasma injection for treatment of osteoarthritis of the knee. Knee Surg Sports Traumatol Arthrosc 24, 1665-1677 (2016). [PubMed: 26387122]

94. Tubach F et al. Evaluation of clinically relevant changes in patient reported outcomes in knee and hip osteoarthritis: the minimal clinically important improvement. Ann. Rheum. Dis 64, 29-33 (2005). [PubMed: 15208174]

95. Escobar A et al. Responsiveness and clinically important differences for the WOMAC and SF-36 after total knee replacement. Osteoarthr. Cartil 15, 273-280 (2007). [PubMed: 17052924]

96. Angst F, Aeschlimann A, Michel BA \& Stucki G Minimal clinically important rehabilitation effects in patients with osteoarthritis of the lower extremities. The Journal of Rheumatology 29, 131-138 (2002). [PubMed: 11824949]

97. Chahla J et al. Concentrated Bone Marrow Aspirate for the Treatment of Chondral Injuries and Osteoarthritis of the Knee: A Systematic Review of Outcomes. Orthop J Sports Med 4, 2325967115625481 (2016). [PubMed: 26798765]

98. Bowen JE Technical issues in harvesting and concentrating stem cells (bone marrow and adipose). PM R 7, S8-18 (2015). [PubMed: 25864664]

99. McCarrel T \& Fortier L Temporal growth factor release from platelet-rich plasma, trehalose lyophilized platelets, and bone marrow aspirate and their effect on tendon and ligament gene expression. J Orthop. Res 27, 1033-1042 (2009). [PubMed: 19170097]

100. Turner L \& Knoepfler P Selling Stem Cells in the USA: Assessing the Direct-to-Consumer Industry. Cell Stem Cell 19, 154-157 (2016). [PubMed: 27374789]

101. Pittenger MF et al. Multilineage potential of adult human mesenchymal stem cells. Science 284 , 143-147 (1999). [PubMed: 10102814]

102. Aronowitz JA, Lockhart RA \& Hakakian CS Mechanical versus enzymatic isolation of stromal vascular fraction cells from adipose tissue. Springerplus 4, 713 (2015). [PubMed: 26636001]

103. Chirba MA, Sweetapple B, Hannon CP \& Anderson JA FDA regulation of adult stem cell therapies as used in sports medicine. J Knee Surg 28, 55-62 (2015). [PubMed: 25603042]

104. Center for Biologics Evaluation. Regulatory Considerations for Human Cells, Tissues, and Cellular and Tissue-Based Products: Minimal Manipulation and Homologous Use. (Code of Federal Regulations, 2017).

105. Marks P \& Gottlieb S Balancing Safety and Innovation for Cell-Based Regenerative Medicine. The New England journal of medicine 378, 954-959 (2018). [PubMed: 29514023]

106. Kokai LE, Marra K \& Rubin JP Adipose stem cells: biology and clinical applications for tissue repair and regeneration. Transl Res 163, 399-408 (2014). [PubMed: 24361334]

107. Oberbauer E et al. Enzymatic and non-enzymatic isolation systems for adipose tissue-derived cells: current state of the art. Cell Regen (Lond) 4, 7 (2015). [PubMed: 26435835]

108. Bourin $\mathrm{P}$ et al. Stromal cells from the adipose tissue-derived stromal vascular fraction and culture expanded adipose tissue-derived stromal/stem cells: a joint statement of the International Federation for Adipose Therapeutics and Science (IFATS) and the International Society for Cellular Therapy (ISCT). Cytotherapy 15, 641-648 (2013). [PubMed: 23570660]

109. Koh Y-G, Choi Y-J, Kwon O-R \& Kim Y-S Second-Look Arthroscopic Evaluation of Cartilage Lesions After Mesenchymal Stem Cell Implantation in Osteoarthritic Knees. The American Journal of Sports Medicine 42, 1628-1637 (2014). [PubMed: 24743139]

110. Koh Y-G, Kwon O-R, Kim YS, Choi Y-J \& Tak D-H Adipose-Derived Mesenchymal Stem Cells With Microfracture Versus Microfracture Alone: 2-Year Follow-up of a Prospective Randomized Trial. Arthroscopy 32, 97-109 (2016). [PubMed: 26585585]

111. Pak J et al. Current use of autologous adipose tissue-derived stromal vascular fraction cells for orthopedic applications. J. Biomed. Sci 24, 9 (2017). [PubMed: 28143470] 
112. Pers Y-M et al. Adipose Mesenchymal Stromal Cell-Based Therapy for Severe Osteoarthritis of the Knee: A Phase I Dose-Escalation Trial. Stem Cells Transl Med 5, 847-856 (2016). [PubMed: 27217345]

113. Fodor PB \& Paulseth SG Adipose Derived Stromal Cell (ADSC) Injections for Pain Management of Osteoarthritis in the Human Knee Joint. Aesthet Surg J36, 229-236 (2016).

114. Mendicino M, Bailey AM, Wonnacott K, Puri RK \& Bauer SR MSC-based product characterization for clinical trials: an FDA perspective. Cell Stem Cell 14, 141-145 (2014). [PubMed: 24506881]

115. Freitag J et al. Mesenchymal stem cell therapy in the treatment of osteoarthritis: reparative pathways, safety and efficacy - a review. BMC Musculoskeletal Disorders 17, 230 (2016). [PubMed: 27229856]

116. Pas HI et al. Stem cell injections in knee osteoarthritis: a systematic review of the literature. British journal of sports medicine bjsports-2016-096793 (2017). doi:10.1136/ bjsports-2016-096793

117. McIntyre JA, Jones IA, Han B \& C Thomas Vangsness J Intra-articular Mesenchymal Stem Cell Therapy for the Human Joint: A Systematic Review. The American Journal of Sports Medicine 11, 036354651773584 (2017).

118. Chahla J et al. Intra-Articular Cellular Therapy for Osteoarthritis and Focal Cartilage Defects of the Knee: A Systematic Review of the Literature and Study Quality Analysis. J Bone Joint Surg Am 98, 1511-1521 (2016). [PubMed: 27655978]

119. Pak J, Lee JH, Park KS, Jeon JH \& Lee SH Potential use of mesenchymal stem cells in human meniscal repair: current insights. Open Access J Sports Med 8, 33-38 (2017). [PubMed: 28356779]

120. Caplan AI Mesenchymal stem cells. J Orthop. Res 9, 641-650 (1991). [PubMed: 1870029]

121. Caplan AI Mesenchymal Stem Cells: Time to Change the Name! Stem Cells Transl Med 6, 14451451 (2017). [PubMed: 28452204]

122. Dominici M et al. Minimal criteria for defining multipotent mesenchymal stromal cells. The International Society for Cellular Therapy position statement. Cytotherapy 8, 315-317 (2006). [PubMed: 16923606]

123. Horwitz EM et al. Clarification of the nomenclature for MSC: The International Society for Cellular Therapy position statement. Cytotherapy 7, 393-395 (2005). [PubMed: 16236628]

124. Bianco P, Robey PG \& Simmons PJ Mesenchymal stem cells: revisiting history, concepts, and assays. Cell Stem Cell 2, 313-319 (2008). [PubMed: 18397751]

125. Stappenbeck TS \& Miyoshi H The role of stromal stem cells in tissue regeneration and wound repair. Science 324, 1666-1669 (2009). [PubMed: 19556498]

126. Galipeau J \& Krampera M The challenge of defining mesenchymal stromal cell potency assays and their potential use as release criteria. Cytotherapy 17, 125-127 (2015). [PubMed: 25593076]

127. Marks PW, Witten CM \& Califf RM Clarifying Stem-Cell Therapy's Benefits and Risks. The New England journal of medicine 376, 1007-1009 (2017). [PubMed: 27959704]

128. Prockop DJ et al. Defining the risks of mesenchymal stromal cell therapy. Cytotherapy 12, 576578 (2010). [PubMed: 20735162]

129. Toyserkani NM et al. Concise Review: A Safety Assessment of Adipose-Derived Cell Therapy in Clinical Trials: A Systematic Review of Reported Adverse Events. Stem Cells Transl Med 6, 1786-1794 (2017). [PubMed: 28722289]

130. Vega A et al. Treatment of Knee Osteoarthritis With Allogeneic Bone Marrow Mesenchymal Stem Cells: A Randomized Controlled Trial. Transplantation 99, 1681-1690 (2015). [PubMed: 25822648]

131. Vangsness CTJ et al. Adult Human Mesenchymal Stem Cells Delivered via Intra-Articular Injection to the Knee Following Partial Medial Meniscectomy: A Randomized, Double-Blind, Controlled Study. 96, 90-98 (2014).

132. Trounson A \& McDonald C Stem Cell Therapies in Clinical Trials: Progress and Challenges. Cell Stem Cell 17, 11-22 (2015). [PubMed: 26140604] 
133. McIntyre JA, Jones IA, Danilkovich A \& Vangsness CT The Placenta: Applications in Orthopaedic Sports Medicine. The American Journal of Sports Medicine 122, 363546517697682 (2017).

134. Goldberg A, Mitchell K, Soans J, Kim L \& Zaidi R The use of mesenchymal stem cells for cartilage repair and regeneration: a systematic review. J Orthop Surg Res 12, 39 (2017). [PubMed: 28279182]

135. Jones IA, Chen X, Evseenko D \& C Thomas Vangsness J Nomenclature Inconsistency and Selective Outcome Reporting Hinders Our Understanding of Stem Cell Therapy for the Knee. Journal of Bone and Joint Surgery-American Volume

136. Shkhyan R et al. Drug-induced modulation of gp130 signalling prevents articular cartilage degeneration and promotes repair. Ann. Rheum. Dis annrheumdis-2017-212037 (2018). doi: 10.1136/annrheumdis-2017-212037

137. Dananberg J A Safety and Tolerability Study of UBX0101 in Patients With Osteoarthritis of the Knee. ClinicalTrials.gov(2018).

138. Jeon $\mathrm{OH}$ et al. Local clearance of senescent cells attenuates the development of post-traumatic osteoarthritis and creates a pro-regenerative environment. Nat. Med 23, 775-781 (2017). [PubMed: 28436958]

139. Lozada CJ et al. A double-blind, randomized, saline-controlled study of the efficacy and safety of co-administered intra-articular injections of Tr14 and Ze14 for treatment of painful osteoarthritis of the knee: The MOZArT trial. European Journal of Integrative Medicine 13, 54-63 (2017).

140. Lei J, Priddy LB, Lim JJ \& Koob TJ Dehydrated Human Amnion/Chorion Membrane (dHACM) Allografts as a Therapy for Orthopedic Tissue Repair. Techniques in Orthopaedics 32, 149-157 (2017).

141. Lei J, Priddy LB, Lim JJ, Massee M \& Koob TJ Identification of Extracellular Matrix Components and Biological Factors in Micronized Dehydrated Human Amnion/Chorion Membrane. Adv Wound Care (New Rochelle) 6, 43-53 (2017). [PubMed: 28224047]

142. US National Library of Medicine. ClinicalTrials.gov, https://clinicaltrials.gov/ct2/show/ NCT03485157(2018).

143. Willett NJ et al. Intra-articular injection of micronized dehydrated human amnion/chorion membrane attenuates osteoarthritis development. Arthritis Res. Ther 16, R47 (2014). [PubMed: 24499554]

144. Shimonkevitz $\mathrm{R}$ et al. A diketopiperazine fragment of human serum albumin modulates Tlymphocyte cytokine production through rap1. J Trauma 64, 35-41 (2008). [PubMed: 18188096]

145. Bar-Or D et al. A randomized clinical trial to evaluate two doses of an intra-articular injection of LMWF-5A in adults with pain due to osteoarthritis of the knee. PLoS ONE 9, e87910 (2014). [PubMed: 24498399]

146. Schwappach J, Dryden SM \& Salottolo KM Preliminary Trial of Intra-articular LMWF-5A for Osteoarthritis of the Knee. Orthopedics 40, e49-e53 (2017). [PubMed: 27684085]

147. Cole B, McGrath B, Salottolo K \& Bar-Or D LMWF-5A for the Treatment of Severe Osteoarthritis of the Knee: Integrated Analysis of Safety and Efficacy. Orthopedics 41, e77-e83 (2018). [PubMed: 29156068]

148. Bar-Or D et al. Low Molecular Weight Fraction of Commercial Human Serum Albumin Induces Morphologic and Transcriptional Changes of Bone Marrow-Derived Mesenchymal Stem Cells. Stem Cells Transl Med 4, 945-955 (2015). [PubMed: 26041739]

149. US National Library of Medicine. ClinicalTrials.gov, https://clinicaltrials.gov/ct2/show/ NCT03349645(2017).

150. Hangody L et al. Intra-articular Injection of a Cross-Linked Sodium Hyaluronate Combined with Triamcinolone Hexacetonide (Cingal) to Provide Symptomatic Relief of Osteoarthritis of the Knee: A Randomized, Double-Blind, Placebo-Controlled Multicenter Clinical Trial. Cartilage 89, 1947603517703732 (2017).

151. US National Library of Medicine. ClinicalTrials.gov, https://clinicaltrials.gov/ct2/show/ NCT02381652(2015).

152. US National Library of Medicine. ClinicalTrials.gov, https://clinicaltrials.gov/ct2/show/ NCT03390036(2017). 
153. O'Shaughnessey K et al. Autologous protein solution prepared from the blood of osteoarthritic patients contains an enhanced profile of anti-inflammatory cytokines and anabolic growth factors. Journal of Orthopaedic Research 32, 1349-1355 (2014). [PubMed: 24981198]

154. Hix J et al. An Autologous Anti-Inflammatory Protein Solution Yielded a Favorable Safety Profile and Significant Pain Relief in an Open-Label Pilot Study of Patients with Osteoarthritis. Biores Open Access 6, 151-158 (2017). [PubMed: 29279807]

155. King W, Bendele A, Marohl T \& Woodell-May J Human blood-based anti-inflammatory solution inhibits osteoarthritis progression in a meniscal-tear rat study. Journal of Orthopaedic Research 35, 2260-2268 (2017). [PubMed: 28139016]

156. Wanstrath AW et al. Evaluation of a Single Intra-Articular Injection of Autologous Protein Solution for Treatment of Osteoarthritis in a Canine Population. Vet Surg 45, 764-774 (2016). [PubMed: 27391909]

157. van Drumpt RAM, van der Weegen W, King W, Toler K \& Macenski MM Safety and Treatment Effectiveness of a Single Autologous Protein Solution Injection in Patients with Knee Osteoarthritis. Biores Open Access 5, 261-268 (2016). [PubMed: 27668131]

158. Kon E, Engebretsen L, Verdonk P, Nehrer S \& Filardo G Clinical Outcomes of Knee Osteoarthritis Treated With an Autologous Protein Solution Injection: A 1Year Pilot DoubleBlinded Randomized Controlled Trial. The American Journal of Sports Medicine 46, 171-180 (2018). [PubMed: 29016185]

159. US National Library of Medicine. ClinicalTrials.gov, https://clinicaltrials.gov/ct2/show/ NCT02138890(2015).

160. US National Library of Medicine. ClinicalTrials.gov, https://clinicaltrials.gov/ct2/show/ NCT02905240(2016).

161. Dell' accio F \& Cailotto F Pharmacological blockade of the WNT-beta-catenin signaling: a possible first-in-kind DMOAD. Osteoarthr. Cartil 26, 4-6 (2018). [PubMed: 29079516]

162. Usami Y, Gunawardena AT, Iwamoto M \& Enomoto-Iwamoto M Wnt signaling in cartilage development and diseases: lessons from animal studies. Lab. Invest 96, 186-196 (2016). [PubMed: 26641070]

163. Deshmukh V et al. A small-molecule inhibitor of the Wnt pathway (SM04690) as a potential disease modifying agent for the treatment of osteoarthritis of the knee. Osteoarthr. Cartil 26, 18 27 (2018). [PubMed: 28888902]

164. Yasuhara $\mathrm{R}$ et al. Roles of $\beta$-catenin signaling in phenotypic expression and proliferation of articular cartilage superficial zone cells. Lab. Invest 91, 1739-1752 (2011). [PubMed: 21968810]

165. Zhu M et al. Inhibition of beta-catenin signaling in articular chondrocytes results in articular cartilage destruction. Arthritis \& Rheumatism 58, 2053-2064 (2008). [PubMed: 18576323]

166. Yazici $Y$ et al. A novel Wnt pathway inhibitor, SM04690, for the treatment of moderate to severe osteoarthritis of the knee: results of a 24-week, randomized, controlled, phase 1 study. Osteoarthr. Cartil 25, 1598-1606 (2017). [PubMed: 28711582]

167. US National Library of Medicine. ClinicalTrials.gov, https://clinicaltrials.gov/ct2/show/ NCT03122860(2017).

168. US National Library of Medicine. ClinicalTrials.gov, https://clinicaltrials.gov/ct2/show/ NCT02536833(2015).

169. Roemer FW et al. Structural effects of sprifermin in knee osteoarthritis: a post-hoc analysis on cartilage and non-cartilaginous tissue alterations in a randomized controlled trial. BMC Musculoskeletal Disorders 17, 267 (2016). [PubMed: 27393009]

170. Eckstein F, Wirth W, Guermazi A, Maschek S \& Aydemir A Brief report: intraarticular sprifermin not only increases cartilage thickness, but also reduces cartilage loss: location-independent post hoc analysis using magnetic resonance imaging. Arthritis Rheumatol 67, 2916-2922 (2015). [PubMed: 26138203]

171. US National Library of Medicine. ClinicalTrials.gov, https:/clinicaltrials.gov/ct2/show/ NCT01919164(2013).

172. Hochberg M, Guermazi A \& H. GO Hochberg MC, Guermazi A, Guehring H, Aydemir A, Wax S, Fleuranceau-Morel P, Bihlet AR, Byrjalsen I, Andersen JR, Eckstein F. Efficacy and Safety of Intra-Articular Sprifermin in Symptomatic Radiographic Knee Osteoarthritis: Results of the 2- 
Year Primary Analysis from a 5Year Randomised, Placebo-Controlled, Phase II Study [abstract]. Arthritis Rheumatol (2017).

173. Caterina MJ \& Julius D The vanilloid receptor: a molecular gateway to the pain pathway. Annu. Rev. Neurosci 24, 487-517 (2001). [PubMed: 11283319]

174. Simone DA, Nolano M, Johnson T, Wendelschafer-Crabb G \& Kennedy WR Intradermal injection of capsaicin in humans produces degeneration and subsequent reinnervation of epidermal nerve fibers: correlation with sensory function. J Neurosci. 18, 8947-8959 (1998). [PubMed: 9787000]

175. Anand P \& Bley K Topical capsaicin for pain management: therapeutic potential and mechanisms of action of the new high-concentration capsaicin 8\% patch. Br J Anaesth 107, 490-502 (2011). [PubMed: 21852280]

176. Remadevi R \& Szallisi A Adlea (ALGRX-4975), an injectable capsaicin (TRPV1 receptor agonist) formulation for longlasting pain relief. IDrugs 11, 120-132 (2008). [PubMed: 18240098]

177. Stevens R et al. OP0167 Efficacy and safety of CNTX-4975 in subjects with moderate to severe osteoarthritis knee pain: 24-week, randomized, double-blind, placebo-controlled, dose-ranging study. Ann. Rheum. Dis 76, 121-121 (2017).

178. Hanson Peter D., et al. "CNTX-4975 administration in subjects with knee pain associated with osteoarthritis: Results of the randomized, double-blind, placebo-controlled, phase $2 b$ TRIUMPH study." IX SIMPAR-ISURA (Study in Multidisciplinary Pain Research-International Symposium of Ultrasound for Regional Anesthesia and Pain Medicine). Florence, Italy2017

179. US National Library of Medicine. ClinicalTrials.gov, https://clinicaltrials.gov/ct2/show/ NCT03429049(2018).

180. Lee DK et al. Continuous transforming growth factor beta1 secretion by cell-mediated gene therapy maintains chondrocyte redifferentiation. Tissue Eng 11, 310-318 (2005). [PubMed: 15738684]

181. Ha C-W, Noh MJ, Choi KB \& Lee KH Initial phase I safety of retrovirally transduced human chondrocytes expressing transforming growth factor-beta-1 in degenerative arthritis patients. Cytotherapy 14, 247-256 (2012). [PubMed: 22242865]

182. Cherian JJ et al. Preliminary results of a phase II randomized study to determine the efficacy and safety of genetically engineered allogeneic human chondrocytes expressing TGF- $\beta 1$ in patients with grade 3 chronic degenerative joint disease of the knee. Osteoarthr. Cartil 23, 2109-2118 (2015). [PubMed: 26188189]

183. Guermazi A et al. Structural effects of intra-articular TGF- $\beta 1$ in moderate to advanced knee osteoarthritis: MRI-based assessment in a randomized controlled trial. BMC Musculoskeletal Disorders 18, 461 (2017). [PubMed: 29145839]

184. Kim M-K et al. A Multicenter, Double-Blind, Phase III Clinical Trial to Evaluate the Efficacy and Safety of a Cell and Gene Therapy in Knee Osteoarthritis Patients. Hum Gene Ther Clin Dev29, 48-59 (2018). [PubMed: 29641281]

185. US National Library of Medicine. ClinicalTrials.gov, https://clinicaltrials.gov/ct2/show/ NCT03203330(2017).

186. Kraus VB et al. Synovial and systemic pharmacokinetics (PK) of triamcinolone acetonide (TA) following intra-articular (IA) injection of an extended-release microsphere-based formulation (FX006) or standard crystalline suspension in patients with knee osteoarthritis (OA). Osteoarthr. Cartil 26, 34-42 (2018). [PubMed: 29024802]

187. Bodick $\mathrm{N}$ et al. An intra-articular, extended-release formulation of triamcinolone acetonide prolongs and amplifies analgesic effect in patients with osteoarthritis of the knee: a randomized clinical trial. J Bone Joint Surg Am 97, 877-888 (2015). [PubMed: 26041848]

188. US National Library of Medicine. ClinicalTrials.gov, https://clinicaltrials.gov/ct2/show/ NCT01487161(2011).

189. Conaghan PG et al. Brief Report: A Phase IIb Trial of a Novel Extended-Release Microsphere Formulation of Triamcinolone Acetonide for Intra-articular Injection in Knee Osteoarthritis. Arthritis Rheumatol 70, 204-211 (2018). [PubMed: 29088579] 
190. Conaghan PG et al. Effects of a Single Intra-Articular Injection of a Microsphere Formulation of Triamcinolone Acetonide on Knee Osteoarthritis Pain: A Double-Blinded, Randomized, PlaceboControlled, Multinational Study. J Bone Joint Surg Am 100, 666-677 (2018). [PubMed: 29664853]

191. Bianco $P$ et al. The meaning, the sense and the significance: translating the science of mesenchymal stem cells into medicine. Nat. Med 19, 35-42 (2013). [PubMed: 23296015]

192. Prockop DJ Repair of tissues by adult stem/progenitor cells (MSCs): controversies, myths, and changing paradigms. Mol. Ther 17, 939-946 (2009). [PubMed: 19337235]

193. Bravery CA et al. Potency assay development for cellular therapy products: an ISCT review of the requirements and experiences in the industry. Cytotherapy 15, 9-19 (2013). [PubMed: 23260082] 


\section{Key points}

- The cost and unclear effectiveness of hyaluronic acid and glucocorticoids have raised concerns over their broad use for osteoarthritis (OA)-related knee pain.

- $\quad$ Self-reported parameters such as pain and stiffness are particularly responsive to intra-articular placebo, which poses challenges when attempting to ascribe clinical meaning to therapeutic interventions.

- $\quad$ Estimates of the minimal (clinically) important difference for patient reported outcomes can provide useful pretext when appraising the effectiveness of intra-articular therapies.

- Lack of data, study heterogeneity and methodological limitations hinder our understanding of point-of-care injectable cell therapies such as platelet-rich plasma, bone marrow aspirate concentrate and adipose tissue-derived treatments.

- The generally positive efficacy conclusions concerning mesenchymal 'stem' cell therapy for knee cartilage pathology might be overstated owing to selective outcome reporting.

- A number of intra-articular therapeutic candidates for OA are currently in clinical development, including small molecule therapies, biologic therapies, gene therapies and novel devices. 


\section{Subject ontology terms}

Health sciences / Diseases / Rheumatic diseases / Osteoarthritis

[URI /692/699/1670/407]

Health sciences / Health care / Therapeutics / Biological therapy

[URI /692/700/565/1331]

Health sciences / Health care / Therapeutics / Drug therapy

[URI /692/700/565/1436]

Health sciences / Health care / Therapeutics / Gene therapy

[URI /692/700/565/201]

Health sciences / Health care / Therapeutics / Stem-cell therapies

[URI /692/700/565/2319] 
Box 1.

Controversies surrounding mesenchymal stem (or stromal) cell therapies.

\section{Terminology}

The term MSC can be used to describe two different types of cells: mesenchymal stem cells and mesenchymal stromal cells. Stem cells are multipotent and can self-renew in vivo ${ }^{191}$. By contrast, stromal cells are loosely defined as plastic-adherent cells that express and/or lack specific cell surface markers and are capable of tri-lineage differentiation into osteoblasts, adipocytes and chondrocytes in vitro ${ }^{108,122}$.

\section{Nomenclature}

The terms marrow stromal cell, multipotent stromal cell, adipose-derived stromal cell and medicinal signalling cell have all been used to describe passaged, plastic-adherent adult multipotent mesenchymal cells ${ }^{121}$. This inconsistent nomenclature reflects the assumed, and not yet fully understood, immunomodulatory and/or immunosuppressive properties that are associated with stromal cell populations ${ }^{126}$, as well as the confusion surrounding the dynamic interactions between cellular niches that help to determine cell fate ${ }^{192}$.

\section{Regulation for use as a therapy}

With respect to their use as an intra-articular therapy in clinical research, true MSCs are classed as drugs that require federal regulatory approval before they can be administered to patients ${ }^{104}$. Although some treatments containing multipotent stromal cell populations might claim to be exempt from FDA regulation (such as so called minimally manipulated cell therapies and certain blood-derived products), these treatments should not be confused with true MSC therapies, as they tend to contain more heterogeneous cell populations than those in true MSC therapies and have effects that are not primarily attributed to their medicinal immunomodulatory and/or immunosuppressive capacity or differentiation potential ${ }^{193}$.

\section{Therapeutic use}

Direct-to-consumer marketing of MSC therapies is widespread in the United States ${ }^{100}$ despite the fact that few high-quality studies have been published ${ }^{118}$. Moreover, the authors of many of the randomized controlled trials that evaluated the efficacy of MSC therapy for knee cartilage pathology have reported intra-group differences and/or intergroup sub-score differences, but have failed to report the original intended outcomes of the studies ${ }^{135}$, suggesting a need for prudence moving forward. Although scientific optimism and enthusiasm is warranted, it is important that patients interested in these treatments understand that a lack of robust data exists to support their use. 


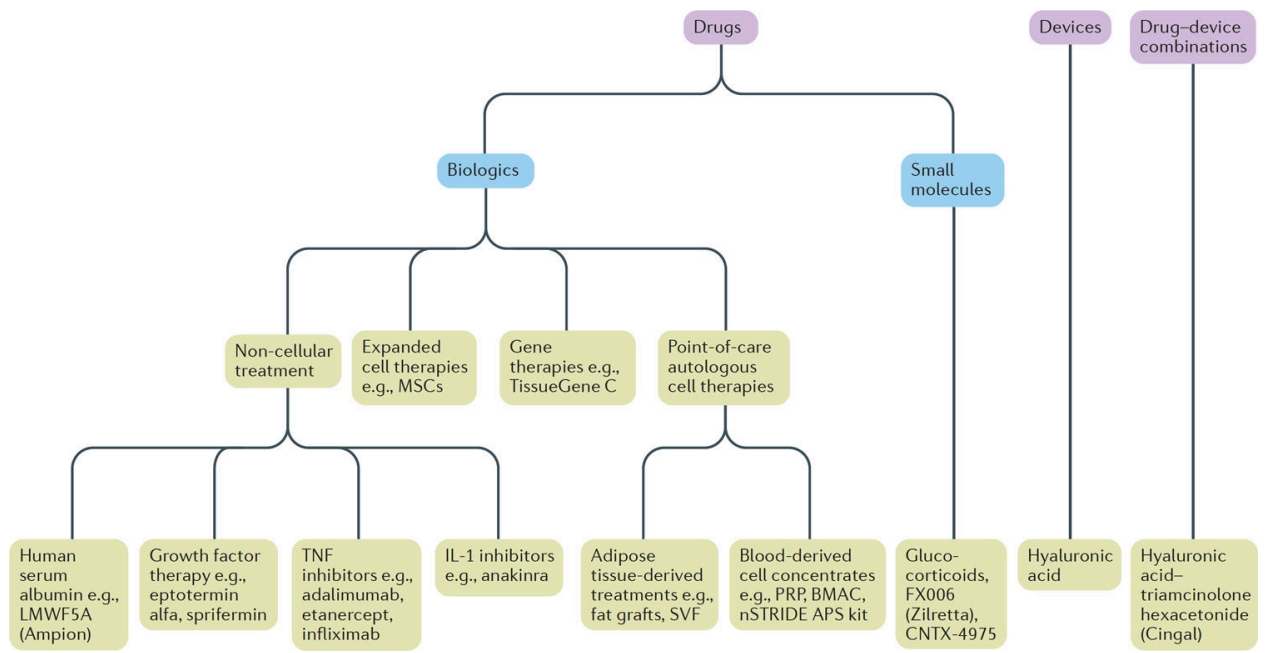

Figure 1. Intra-articular treatments for osteoarthritis.

Intra-articular treatments for osteoarthritis are approved by the FDA as drugs, devices or drug-device combination products. Drugs are classified as small molecules (<900 Daltons) or biologics, which can be further broken down into four sub-categories (non-cellular therapies, expanded cell therapies, gene therapies and point-of-care autologous cell therapies). The therapeutic effects of non-cellular biologic drugs depend on single large complex molecules or on specific mixtures of molecules. For the sake of simplicity, only clinically investigated human serum albumin, TNF inhibitors, IL-1 inhibitors and growth factors are included. Expanded cell therapies are biologic drug 'factories' that are subject to strict regulatory oversight, whereas gene therapies introduce genes that make beneficial protein(s) or compensate for abnormal genes. Point-of-care autologous cell therapies are heterogeneous mixtures containing cells (or cell products) that are derived from autologous blood, bone marrow or adipose tissue and are often given to patients off-label. APS, autologous protein solution; BMAC, bone marrow aspirate concentrate; MSC, mesenchymal stem cell; PRP, platelet-rich plasma; SVF, stromal vascular fraction. 

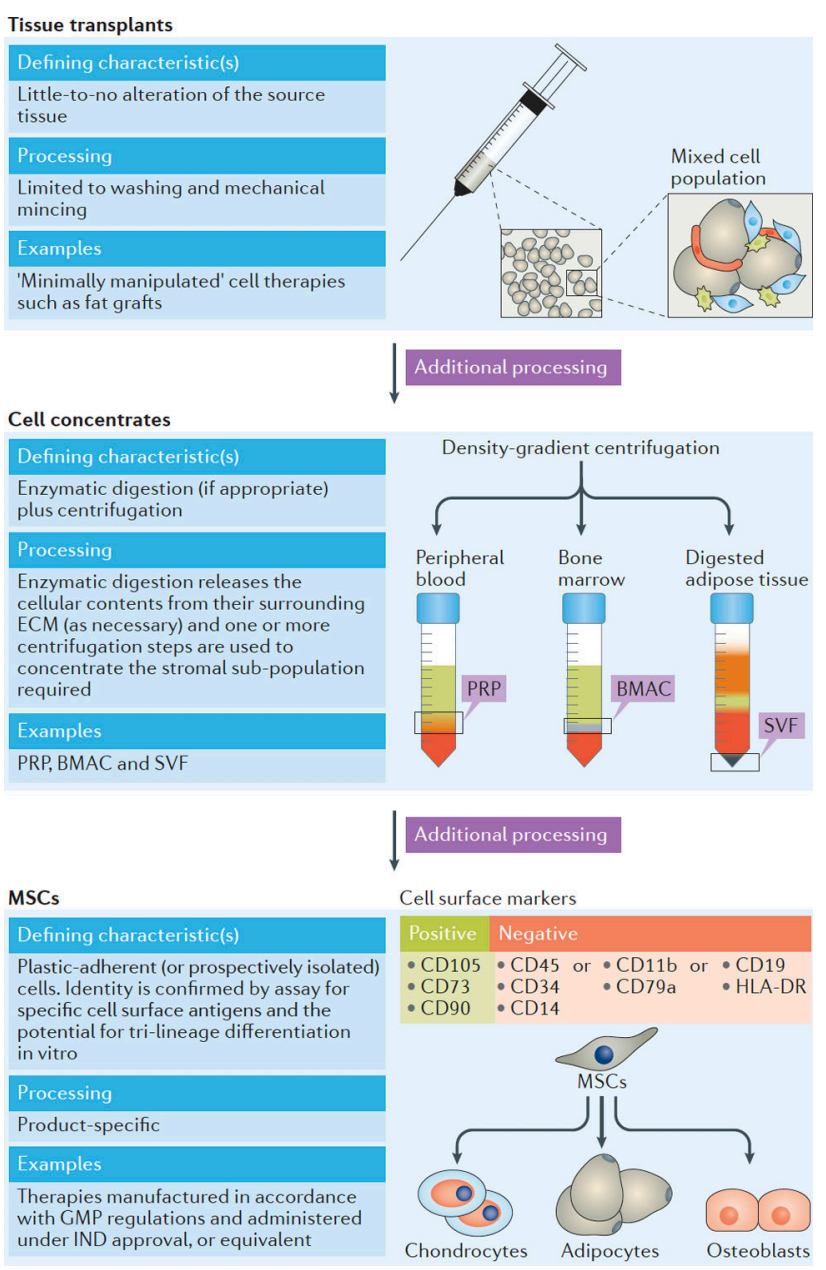

Figure 2. Intra-articular cell therapies.

Cell therapies can be broadly characterized by the method used to produce them or, because processing tissue concentrates specific cell population(s), by their relative heterogeneity compared with the source tissue. Intra-articular tissue injections (such as fat grafts) are the least processed and most heterogeneous treatments, whereas mesenchymal stromal (or stem) cells (MSCs) are the most processed and least heterogeneous. Within each treatment category, therapies (and the regulations governing their clinical use) tend to differ widely. As such, treatment categories should only be used as a conceptual framework and should not be used to draw false equivalencies concerning the efficacy or safety of different treatments.

BMAC, bone marrow aspirate concentrate; GMP, good manufacturing practices; IND, investigational new drug, PRP, platelet-rich plasma; SVF, stromal vascular fraction. 


\begin{tabular}{|l|l|} 
& \multicolumn{1}{c}{$\begin{array}{c}\text { Clinical development } \\
\text { Phase I Phase II }\end{array}$} \\
\hline $\begin{array}{l}\text { LWMF5A (Ampion) } \\
\text { Ampion } \\
\text { Pharmaceuticals Inc }\end{array}$ \\
\hline $\begin{array}{l}\text { Hyaluronic acid-triamcinolone } \\
\text { hexacetonide (Cingal) } \\
\text { Anika Therapeutics, Inc }\end{array}$ \\
\hline $\begin{array}{l}\text { nSTRIDE APS kit } \\
\text { Zimmer Biomet }\end{array}$ \\
\hline $\begin{array}{l}\text { SM04690 III/IV } \\
\text { Samumed LLC }\end{array}$ \\
\hline $\begin{array}{l}\text { Sprifermin } \\
\text { EMD Serono }\end{array}$ \\
\hline $\begin{array}{l}\text { CNTX-4975 } \\
\text { Centrexion Therapeutics } \\
\text { Corporation }\end{array}$ \\
\hline $\begin{array}{l}\text { TissueGene C } \\
\text { TissueGene, Inc. }\end{array}$ \\
\hline $\begin{array}{l}\text { FX006 (Zilretta) } \\
\text { Flexion } \\
\text { Therapeutics Inc. }\end{array}$ \\
\hline
\end{tabular}

Figure 3. Intra-articular osteoarthritis therapy pipeline.

Current developmental status of intra-articular therapies for osteoarthritis. The information in this figure is derived from clinicaltrials.gov listings and company press releases, and does not reflect or provide an approximate time to market. 
Table 1.

Hyaluronic acid and glucocorticoids to treat osteoarthritis* .

\begin{tabular}{|l|l|l|l|l|}
\hline & $\begin{array}{l}\text { American Academy of } \\
\text { Orthopaedic Surgeons } \\
\mathbf{( 2 0 1 3}^{\mathbf{4 0}}\end{array}$ & $\begin{array}{l}\text { Osteoarthritis } \\
\text { Research Society } \\
\text { International (2014) }\end{array}$ & $\begin{array}{l}\text { National Institute for Health } \\
\text { and Care Excellence (2014) }\end{array}$ & $\begin{array}{l}\text { American College of } \\
\text { Rheumatology (2012) }^{\mathbf{5 2}}\end{array}$ \\
\hline Hyaluronic acid & Not recommended & Inconclusive & Not recommended & Inconclusive \\
\hline Glucocorticoids & Inconclusive & Recommended & Recommended & Recommended \\
\hline
\end{tabular}

* Selected clinical guidelines published in tne past 10 years. 
Table 2.

Clinical trials using intra-articular biologic therapies to treat osteoarthritis.

\begin{tabular}{|l|l|l|l|l|l|}
\hline Study (year) & Therapy & Study size (groups) & Final follow-up & Outcomes & Ref \\
\hline $\begin{array}{l}\text { Chevalier et al. } \\
(2009)\end{array}$ & Anakinra (rhIL-1Ra) & $\begin{array}{l}170(101 \text { anakinra, } 69 \\
\text { placebo) }\end{array}$ & 12 weeks & $\begin{array}{l}\text { Low dose anikara was inferior to } \\
\text { placebo on pain score } \\
\text { High dose anikara was superior } \\
\text { to placebo on pain score }\end{array}$ & 71 \\
\hline $\begin{array}{l}\text { Ohtori et al. } \\
(2015)\end{array}$ & Etanercept (anti-TNF) & $39(19$ etanercept, 20 HA) & 4 weeks & $\begin{array}{l}\text { Etanercept was inferior to HA for } \\
\text { VAS, WOMAC pain score, } \\
\text { WOMAC stiffness score, } \\
\text { WOMAC physical function score } \\
\text { and total WOMAC score }\end{array}$ & 77 \\
\hline $\begin{array}{l}\text { Hunter et al. } \\
(2010)\end{array}$ & Eptotermin alfa (rhBMP7) & $\begin{array}{l}33(25 \text { eptotermin alfa, } 8 \\
\text { placebo) }\end{array}$ & 24 weeks & $\begin{array}{l}\text { Eptotermin alfa was superior to } \\
\text { placebo for achieving WOMAC } \\
\text { pain 20\%, 50\% and 70\% } \\
\text { reduction scores }\end{array}$ & 79 \\
\hline $\begin{array}{l}\text { Lohmander et al. } \\
(2014)\end{array}$ & Sprifermin (rhFGF18) & $\begin{array}{l}192(126 \text { sprifermin, } 42 \\
\text { placebo) }\end{array}$ & 52 weeks & $\begin{array}{l}\text { Sprifermin was superior to } \\
\text { placebo for WOMAC pain scores } \\
\text { and showed a dose dependent } \\
\text { response }\end{array}$ & 80 \\
\hline
\end{tabular}

BMP7, bone morphogenic protein 7; FGF18, fibroblast growth factor 18; HA, hyaluronic acid; IL-1Ra, IL-1 receptor antagonist; VAS, visual analogue scale; WOMAC, Western Ontario and McMaster Universities osteoarthritis index. 